\title{
Computational and Experimental Study of the Effect of Operating Parameters on Classification Performance of Compound Hydrocyclone
}

\author{
Jin Jiang, ${ }^{1}$ Rui Ying $\left(\mathbb{D},{ }^{1}\right.$ Jingan Feng, ${ }^{2}$ and Weibing Wang ${ }^{2}$ \\ ${ }^{1}$ Key Lab of Hydraulic Machinery Transient, MOE, Wuhan University, Wuhan 430072, China \\ ${ }^{2}$ College of Mechanical \& Electrical Engineering, Shihezi University, Shihezi 832003, China \\ Correspondence should be addressed to Rui Ying; yrfhtd@126.com
}

Received 3 January 2018; Revised 3 March 2018; Accepted 15 March 2018; Published 29 April 2018

Academic Editor: Xesús Nogueira

Copyright (C) 2018 Jin Jiang et al. This is an open access article distributed under the Creative Commons Attribution License, which permits unrestricted use, distribution, and reproduction in any medium, provided the original work is properly cited.

Compound hydrocyclone is a kind of dynamic hydrocyclone also with the advantages of static hydrocyclone. In this investigation, the effect of operating parameters on separation performance of compound hydrocyclone is studied using both CFD technique and experimental method. The flow field of compound hydrocyclone was simulated by the RSM turbulence model; the particles with different size were simplified to 6 phases and simulated by the mixture multiphase model. The central composite design method was used to conduct the separation experiment of compound hydrocyclone. The results indicated that compound hydrocyclone can be used for finer particles separation and the flow field of compound hydrocyclone can still achieve a higher centrifugal force in lower inlet velocity. When the minimum partition size is required, the optimized operating condition of the compound hydrocyclone is $\mathbf{v}=2.5 \mathrm{~m} / \mathrm{s}, \mathbf{n}=1865 \mathrm{rpm}$, and $\mathbf{c}=7.5 \%$, while when the maximum partition size is required, the optimized operating condition is $\mathbf{v}=2.5 \mathrm{~m} / \mathrm{s}, \mathbf{n}=905 \mathrm{rpm}$, and $\mathbf{c}=24.5 \%$.

\section{Introduction}

Hydrocyclones are widely used for particle separation and classification in chemical, mineral, and power industries, mainly due to their simple structure, high capacity, low operating and maintenance, and small space occupation. For normal static hydrocyclones, there are still many problems and limitations [1], such that (1) the kinetic energy of the flow field is converted by pressure; thus a higher inlet pressure is required to ensure the centrifugal intensity of the flow field; (2) the short-circuit flow in flow field can result in the overflow with more coarse particles, which seriously impact the separation accuracy; (3) for different materials and requirements, the application scope of static hydrocyclone is limited. A great number of improvements on static hydrocyclone have been proposed and the corresponding research works have been carried out by the investigators. Boadway [2] has improved the vortex finder pipe to a gradual expansion pipe, so that the discharge ability of vortex finder pipe was enhanced and the energy consumption was reduced by $20 \%$. Larsson [3] has proposed the 3D spiral inlet. This inlet structure can effectively reduce the turbulence and fluctuation near the inlet region of hydrocyclone. Chu et al. [4] have invented the hydrocyclone which is the vortex finder pipe with annular teeth. This improvement can effectively restrain the shortcircuit flow and improve the separation accuracy. Evans et al. [5] and Sripriya et al. [6] have designed a hydrocyclone with insertion solid rod to eliminate the air core. The solid rod can greatly reduce the kinetic energy dissipation and stabilizing the flow field. Ghodrat et al. $[7,8]$ proposed a hydrocyclone with convex conical section. Compared to the conventional design, the new hydrocyclone has larger separation region and smaller pressure drop. Ghodrat et al. $[7,8]$ also analyzed the performance of hydrocyclone with different vortex finder, and a compromised optimum configuration has been proposed. The structure improvements of hydrocyclones can reduce the energy consumption of the flow field to a certain extent and improve the efficiency. 
But these improvements have failed to break through the limitations which are the hydrocyclone without energy input, while the dynamic hydrocyclone is a good solution to this problem. Compared to the conventional static hydrocyclone, the dynamic hydrocyclone can also get a higher separation efficiency and a variable capacity.

Compound hydrocyclone is a new form of dynamic hydrocyclones, which has structure characteristics of the normal static hydrocyclone. Because of the acceleration effect of rotating blades, higher separation efficiency can still be obtained in compound hydrocyclone at lower inlet pressure. Liu et al. [9] carried out a test research on oil-water separation of compound hydrocyclone. They found that higher rotating speed will result in seriously emulsification of oil phase. Jiang et al. [10] experimentally optimized the rotating blade structure of deoiling compound hydrocyclone and raised the separation performance. They suggested that the advantages of compound hydrocyclone in terms of flow field energy consumption, separation efficiency, and application scope are that the static hydrocyclone cannot be achieved. Wang [11] investigated the influence of geometric and operation parameters of compound hydrocyclone to deoiling performance and suggested that appropriate rotating speed ranges from $1700 \mathrm{rpm}$ to $2400 \mathrm{rpm}$. Li et al. [12] investigated the effect of vibration behavior on the flow field and separation performance. They found that the flow rate and the electric motor running not only cause the vibration but also affect the separation accuracy. Liu et al. [13] investigated the radial pressure distribution of compound hydrocyclone flow field and determined the general equation of the unit production ability of compound hydrocyclones. Ying et al. [14] made an experimental prototype of compound hydrocyclone for particle separation, of which experimental result indicated that the compound hydrocyclone has a good performance for finer particle separation. So far the compound hydrocyclone is mainly used for oil-water separation in petroleum industry, while the investigation of the compound hydrocyclones applied in the field of particle separation are relatively few. In this investigation, the effect of operating condition on compound hydrocyclone performance is studied using both CFD technique and experimental method. The compound hydrocyclone with different operating parameters was simulated by RSM turbulence model, and the particle phase in the flow field is simulated by mixture multiphase model. The central composite design was used for the experiment and the mathematical models of evaluation indexes were established by nonlinear regression method.

\section{Experimental Aspects}

2.1. Experimental Equipment. The internal structure of compound hydrocyclone is displayed in Figure 1(a). It can be seen that a driving device (rotation blade) is installed in the compound hydrocyclone, which is the main difference with static hydrocyclone. The shaft of rotation blade is attached to an electric motor, so that the fluid in compound hydrocyclone can be accelerated. Meanwhile, the shaft of rotation blade is also used as the vortex finder pipe of hydrocyclone, so that the fluid can flow into the overflow chamber through the shaft.
TABLE 1: Structure parameters of hydrocyclone.

\begin{tabular}{lcc}
\hline Parameters & Symbols & Value \\
\hline Inlet diameter & $\mathbf{D}_{\mathbf{i}}$ & $14 \mathrm{~mm}$ \\
Vortex finder diameter & $\mathbf{D}_{\mathbf{o}}$ & $20 \mathrm{~mm}$ \\
Apex diameter & $\mathbf{D}_{\mathbf{u}}$ & $10 \mathrm{~mm}$ \\
Cylindrical diameter & $\mathbf{D}$ & $75 \mathrm{~mm}$ \\
Rotating blade diameter & $\mathbf{d}$ & $65 \mathrm{~mm}$ \\
Cylindrical length & $\mathbf{L}$ & $40 \mathrm{~mm}$ \\
Rotating blade length & $\mathbf{1}$ & $55 \mathrm{~mm}$ \\
Cone angle & $\boldsymbol{\theta}$ & $6^{\circ}$ \\
\hline
\end{tabular}

In this investigation, the experimental system is a circulation loop mainly composed of water tank, slurry pump, and compound hydrocyclone. The details of experimental system can be seen from Figures 1(c) and 1(d). A branch pipe is set before the inlet of compound hydrocyclone such that the inlet velocity can be regulated by changing the valve opening of branch pipe. Electromagnetic flowmeters (EMF) and pressure gauges are installed on the inlet pipe and the overflow pipe, so that the data of flow rate and pressure can be collected. Rotating speed of electric motor is regulated by the variable-frequency drive (VFD) and the value of rotating speed is measured by a laser tachometer. In order to make the liquid and solid in the water tank mix evenly, a mixing machine is installed above the water tank.

Structure parameters of compound hydrocyclone used in this investigation were determined in the literature [14]. Details of structure parameters can be seen from Table 1 and the symbols of structure parameters can be seen from Figure 1(b). The main body of compound hydrocyclone is made of wear-resistant polyurethane. The rotating blade is made of nylon and blades number is six. Solid particles used in this experiment are $\mathrm{Ca}(\mathrm{OH})_{2}$ particles which are slightly soluble in water $(1.65 \mathrm{~g} / \mathrm{L})$ and the vacuum density of particles is $2234 \mathrm{~kg} / \mathrm{m}^{3}$. Before mixture preparation, few $\mathrm{Ca}(\mathrm{OH})_{2}$ particles should be added to water to make the liquid saturated. Particle size is normal distribution and ranges from $6 \sim 498 \mu \mathrm{m}$ (measured after mixing with water). The distribution of particle size is presented in Figure 2.

2.2. Operating Parameters and Indexes. Operating parameters are the main factors that affect the classification and separation performance of hydrocyclone, including temperature, solid density, particle size distribution, inlet velocity, feed concentration, and setting angle [15]. The previous studies of static hydrocyclone show that inlet velocity and feed concentration (in mass) are the two most influential factors; therefore, the effect of these two parameters on compound hydrocyclone needs to be considered in this paper. On the other hand, rotating blade is the important component of compound hydrocyclone and has a great influence on the flow field. Thus the effect of rotating speed also needs to be considered.

In order to reflect the effects of the operating conditions on the performance of compound hydrocyclone, three 


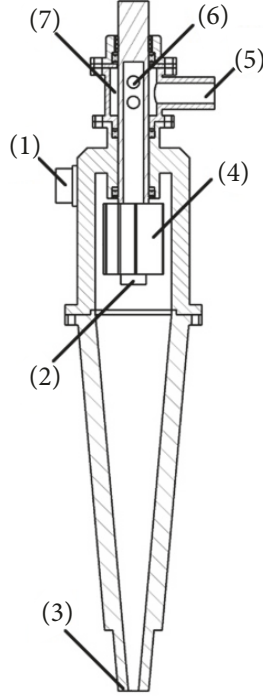

(a)

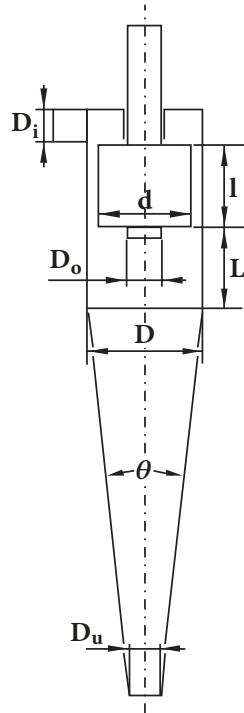

(b)

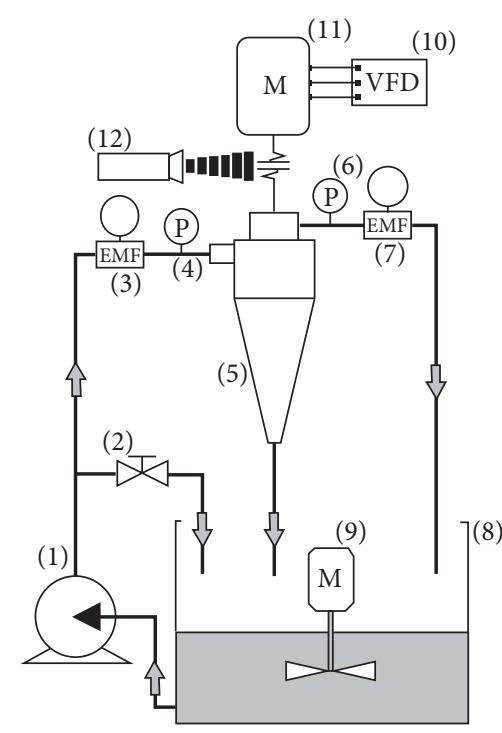

(c)

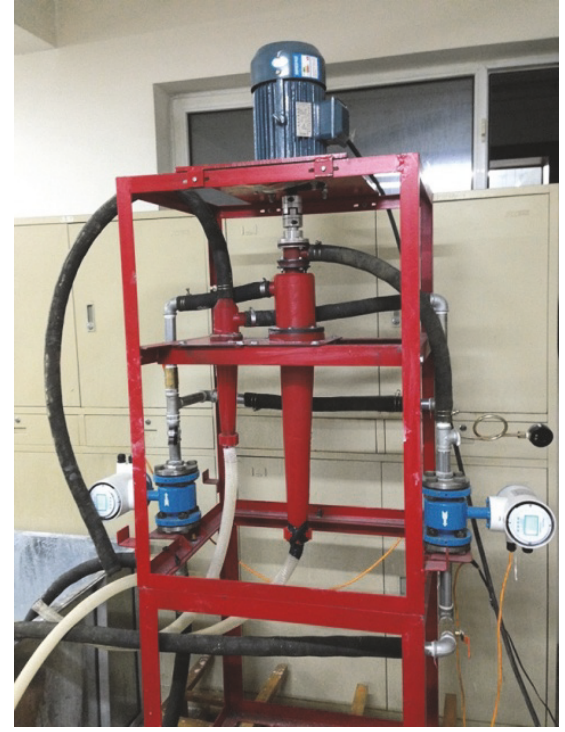

(d)

FIGURE 1: Experimental device and system. (a) Internal structure view of compound hydrocyclone ((1) inlet pipe; (2) vertex finder pipe; (3) apex pipe; (4) rotating blade; (5) overflow outlet; (6) holes; (7) overflow chamber). (b) The symbols of structure parameters. (c) Diagram of experimental system ((1) slurry pump; (2) split-flow valve; (3) and (7) electromagnetic flowmeter; (4) and (6) pressure gauge; (5) compound hydrocyclone; (8) water tank; (9) mixing machine; (10) variable-frequency drive; (11) electric motor; (12) laser tachometer). (d) The photo of experimental system.

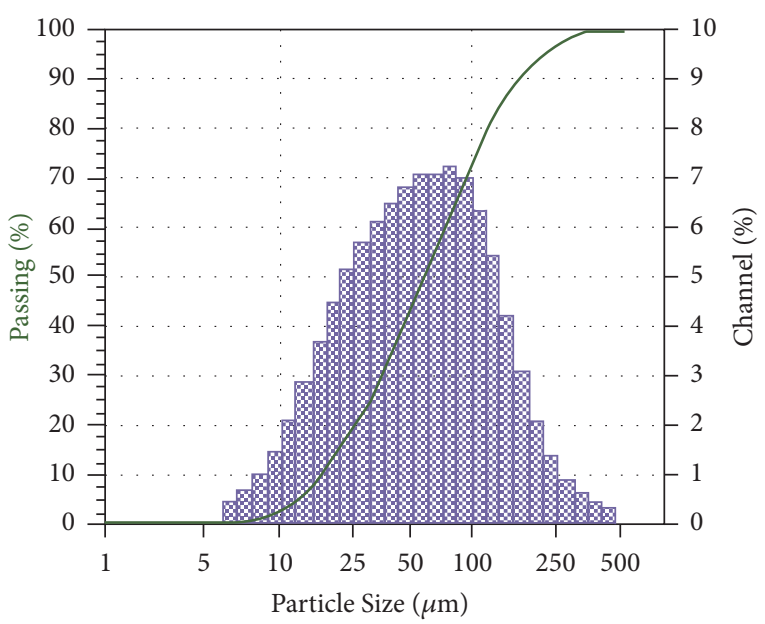

FIGURE 2: Distribution of particle size.

evaluation indexes were selected according to the literature [16]; the indexes are as follows:

(a) Partition size $\left(\mathbf{D}_{50}\right.$; the particle size which has $50 \%$ grade efficiency): this is an important index to evaluate the classification and separation performance of compound hydrocyclone. This index was calculated from the particle distribution of overflow, and the particle distribution was measured by the Laser Particle Size Analyzer.

(b) Split ratio (S; the ratio of volume flow of overflow to volume flow of inlet): this index directly reflects the situation of flow distribution of compound hydrocyclone.

(c) Total efficiency (E; the ratio of particle mass in the underflow to the inlet): this is an important index to evaluate the production capacity and efficiency of compound hydrocyclone.

2.3. Experimental Method. Central composite design is a statistical mathematical method widely used in engineering problem analysis and modeling. It can be used for the nonlinear evaluation of between operating parameters and indexes, and then operating conditions can be optimized by the response surface [17]. In this paper, the classification experiment of compound hydrocyclone was carried out by central composite design method. The mathematical relationship between operating parameters and evaluation indexes was modeled by multivariate nonlinear regression analysis. Based on the mathematical models, the effect of operating parameters and their interactions on the indexes can be analyzed.

The experiment scheme was designed by the commercial software Design-Expert. According to the experimental requirements, fifteen groups of the experiments should be carried out at least and the experiment matrix is comprised of 4 factorial points, 6 axial points, and 5 center points. For this compound hydrocyclone, the inlet velocity range is from 0.5 to $2.5 \mathrm{~m} / \mathrm{s}$; the rotating speed range is 450 to $2950 \mathrm{rpm}$; the feed concentration (in mass) range is 7.5 to $24.5 \%$. Each experimental factor was set to five levels and the details are presented in Table 2. 
TABLE 2: List of factors and different levels.

\begin{tabular}{lcccccc}
\hline \multirow{2}{*}{ Number } & Factors & \multicolumn{2}{c}{ Levels } & High $(+1)$ & Max $(+1.68)$ \\
\hline 1 & Inlet velocity, m/s (v) & 0.5 & 0.8 & 1.5 & 2.2 & 2.5 \\
2 & Rotating speed, rpm (n) & 450 & 800 & 1700 & 2600 & 2950 \\
3 & Feed concentration, \% (c) & 7.5 & 10 & 16 & 22 & 24.5 \\
\hline
\end{tabular}

\section{Numerical Simulation Method}

3.1. Numerical Model. With the development of computer technology, the computational fluid dynamics (CFD) approach is widely used in the investigation of the flow field in hydrocyclone, and the accurate predictions can be obtained. In this investigation, the mixture model is adopted to simulate the solid-liquid multiphase flow in compound hydrocyclone. Mixture model is a simplified TFM model, which allows the interpenetrating and the relative sliding between solid phase and liquid phase [18]. This multiphase model is applicable to simulating the flow flied with an extensive particle distribution. The equations of continuity and momentum for mixture model as follows:

$$
\begin{aligned}
& \frac{\partial \rho_{m}}{\partial t}+\frac{\partial\left(\rho_{m} u_{m i}\right)}{\partial x_{i}}=0 \\
& \frac{\partial\left(\rho_{m} u_{m i}\right)}{\partial t}+\frac{\partial\left(\rho_{m} u_{m i} u_{m j}\right)}{\partial x_{j}} \\
& =-\frac{\partial P}{\partial x_{i}}+\frac{\partial P_{s}}{\partial x_{i}}+\frac{\partial \tau_{m i j}}{\partial x_{j}}+\frac{\partial\left(-\rho_{m} \overline{u_{m i}^{\prime} u_{m j}^{\prime}}\right)}{\partial x_{j}} \\
& \quad+\frac{\partial}{\partial x_{j}}\left(\sum_{k=1}^{n} \rho_{k} u_{\mathrm{dr}, k i} u_{\mathrm{dr}, k j}\right)+g \rho_{m},
\end{aligned}
$$

where $\rho_{m}, u_{m}, \mu_{m}$, and $P_{s}$ represent the density, velocity, and viscosity of the mixture and the pressure of total solid phase, respectively.

In (2), the viscous stress of mixture $\tau_{m}$ and the drift velocity of the $k$ th phase $u_{\mathrm{dr}, k}$ are, respectively, given by

$$
\begin{aligned}
\tau_{m, i j}= & \mu_{m}\left(\frac{\partial u_{m j}}{\partial x_{i}}+\frac{\partial u_{m i}}{\partial x_{j}}\right) \\
u_{\mathrm{dr}, k i}= & \frac{\left(\rho_{k}-\rho_{m}\right) d_{k}^{2}}{18 \mu_{w} f} a_{k i}-\frac{4 \eta_{t}}{3}\left(\frac{\nabla \alpha_{k}}{\alpha_{k}}-\frac{\nabla \alpha_{w}}{\alpha_{w}}\right) \\
& -\sum_{k=1}^{n}\left(\frac{\alpha_{k} \rho_{k} u_{w k, i}}{\rho_{m}}\right),
\end{aligned}
$$

where $\mu_{w}, \alpha_{w}$ represent the viscosity and volume fraction of the primary phase (water). $\rho_{k}, \alpha_{k}, d_{k}$, and $a_{k}$ represent the density, volume fraction, diameter, and acceleration of phase $k . u_{w k, i}$ is the velocity of water phase relative to the velocity of phase $k . \eta_{t}$ is the turbulent diffusivity.
When the volume fraction of solid phase is under 0.8 , the drag force on particles $f$ is determined by Ergun [19] and Wen and $\mathrm{Yu}[20]$, given by following equation:

$$
f=\frac{C_{D}}{24 \mu_{w}} \alpha_{w}^{-1.65} \rho_{w} d_{k}\left|u_{w}-u_{k}\right| .
$$

In previous studies of hydrocyclone, Reynolds stress model (RSM) and large eddy simulation (LES) are widely used in the turbulence simulation of hydrocyclone [21]. For LES method, a sufficient number of boundary layer grids needs to be meshed to ensure the $Y^{+} \leq 1$ in the near wall area, which is the necessary condition for LES [22]. However, the LES needs a large number of meshes to produce valid results. More importantly, in Fluent software, the mixture model cannot be adopted for LES simulation [23].

In this investigation, the turbulence flow in compound hydrocyclone is modeled by RSM model; thus the stress term $-\rho \overline{u_{i}^{\prime} u_{j}^{\prime}}$ in (2) is closed by the Reynolds stress transport equation in

$$
\begin{aligned}
& \frac{\partial\left(\rho \overline{u_{i}^{\prime} u_{j}^{\prime}}\right)}{\partial t}+\frac{\partial\left(\rho u_{k} \overline{u_{i}^{\prime} u_{j}^{\prime}}\right)}{\partial x_{k}} \\
& =D_{T, i j}+G_{i j}+\phi_{i j}-\varepsilon_{i j}+P_{i j}
\end{aligned}
$$

where $D_{T, i j}, G_{i j}, \phi_{i j}, \varepsilon_{i j}$, and $P_{i j}$, respectively, represent the turbulent diffusion term, the buoyancy production term, the pressure strain term, the dissipation term, and stress production term.

3.2. Meshing and Boundary Conditions. In this study, the commercial software GAMBIT was used for meshing the flow field model of compound hydrocyclone. The computational domain of compound hydrocyclone consists of the "stable zone" and the "dynamic zone" where the rotation blades are located, as shown in Figure 3. Block-structured grid generation method was applied to mesh the computational domain, and the grids near the central region were refined to capture the evolution of pressure and velocity gradient; in addition, the grid size of the conical part was gradually reduced in a certain ratio, which can avoid a larger residual of continuity equation caused by higher grids aspect ratio. Since the grid nodes of dynamic and stable zone cannot be matched, these two zones were connected by "interface boundary."

The quality and number of CFD meshes are very important for obtaining meaningful numerical results. Therefore, the entire flow field of compound hydrocyclone was discretized by hexahedral grids, so that the grid quality can get a higher level. Meanwhile, the grid-independent test was 


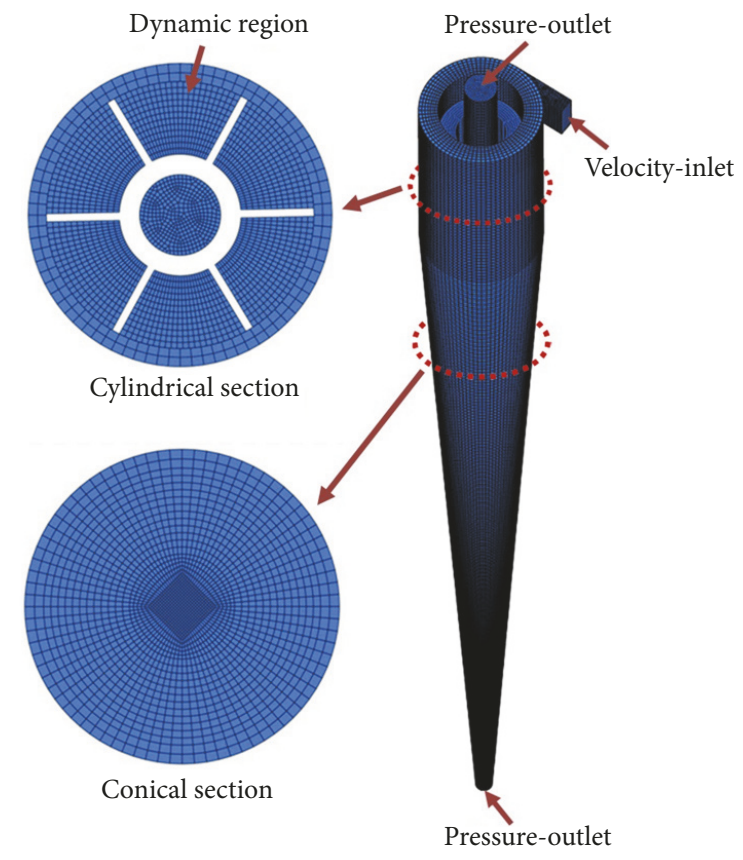

FIGURE 3: Mesh representation of compound hydrocyclone.

performed by gradually decreasing the grid size, which can exclude the impact of grids number on simulation results. Taking into account the length of calculation time, the number of grids was eventually set to 1.5 million.

3.3. Simulation Strategy. The simulation model in this work was developed by Kuang et al. [18]. A two-step work was conducted in this simulation. In step 1 , only air and water were considered, the turbulent flow in compound hydrocyclone was modeled by RSM model, and the interface between water and air core was modeled by Volume of Fluid (VOF) model. The primary air core shape and velocity distribution can be gained in this step. In step 2, the simulation starts with the results from step 1 and the multiphase model was changed from VOF to mixture, so that the liquid-particle flow in compound hydrocyclone can be simulated. This simulation model has already been proved to be valid for hydrocyclone $[18,24]$.

In the setting of boundary conditions, the "velocity inlet" was used for hydrocyclone's inlet, and the inlet velocity was $0.5,1.5$, and $2.5 \mathrm{~m} / \mathrm{s}$, respectively; the "pressure outlet" was used for hydrocyclone's overflow and underflow and the pressure at the two outlets was $1 \mathrm{~atm}$ (standard atmospheric pressure); the "Moving mesh" model was used to simulate the rotation of dynamic zone, and the rotating speed was 450,1700 , and $2950 \mathrm{rpm}$, respectively; the inlet speed of solid phase is the same as that of liquid phase, and the concentration of solid phase was $7.5 \%, 16 \%$, and $24.5 \%$, respectively. In order to ensure the numerical stability, the number of solid phase sizes was simplified to 6 types (10, $25,50,100,150$, and $250 \mu \mathrm{m}$; the proportion is $25,15,22,12$, 14 , and $12 \%$, resp.). In the setting of solution controls, the SIMPLE-Consistent (SIMPLEC) algorithm was used for the

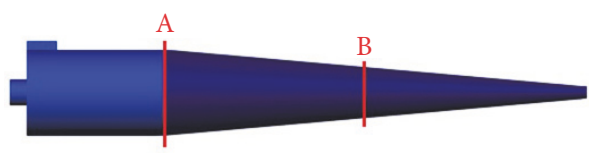

FIGURE 4: Two representative positions.

pressure-velocity coupling; the PRESTO! scheme was taken for spatial discretization of the pressure term; the quadratic upwind interpolation (QUICK) scheme was taken for spatial discretization of the advection terms. The convergence strategy uses the unsteady solver and the time step is $10^{-3} \mathrm{~s}$.

\section{Results and Discussion}

For better describing the effect of each operating parameters on the flow field of compound hydrocyclone, two representative positions in compound hydrocyclone were selected to illustrate the evolution of flow field. As shown in Figure 4, "position A" is the interface between the cylindrical part and the conical part and "position B" is the middle cross-section of the conical part.

4.1. CFD Model Validation. It is necessary to validate the accuracy and rationality of the CFD model. At present, the velocity distribution of multiphase flow field in hydrocyclone is difficult to be obtained by experiment. So that, only split ratio and total efficiency were discussed here for model validation. Figure 5(a) compares the split ratio observed in classification experiment and CFD simulation results, in different inlet velocities. It can be seen that the split ratio of simulation is higher than experiment results. In the condition of lower inlet velocity, a bigger prediction error is observed and the maximum error is $11 \%$. However, the split ratio variation trend of CFD simulation is basically the same with classification experiment. Figure 5(b) compares the experimental results and simulation results of total efficiency at different rotating speeds. It can be seen that the total efficiency of simulation is lower than experiment results, while the variation trend of total efficiency can be correctly predicted by simulation. The maximum error is observed at the rotating speed of $2950 \mathrm{rpm}$ and the value of maximum error is about $7 \%$. The above results indicate that this CFD model can at least make a qualitative analysis of compound hydrocyclone's performance. However, the solid phase was simplified by mixture model and the particle distribution cannot be presented exactly. Therefore, an accurate quantitative analysis of compound hydrocyclone is difficult to achieve.

4.2. The Effect of Inlet Velocity (v) on Flow Field. The evolution of tangential velocity in different inlet velocities is shown in Figures 6(a) and 6(b). It can be seen that, with the increase of inlet velocity, the tangential velocity of inner vortex (forced vortex) is gradually increased, while the tangential velocity of outer vortex (free vortex) has no obvious changes. This indicates that the outer vortex is accelerated to the same speed as the rotating blade and is not affected by inlet velocity. 


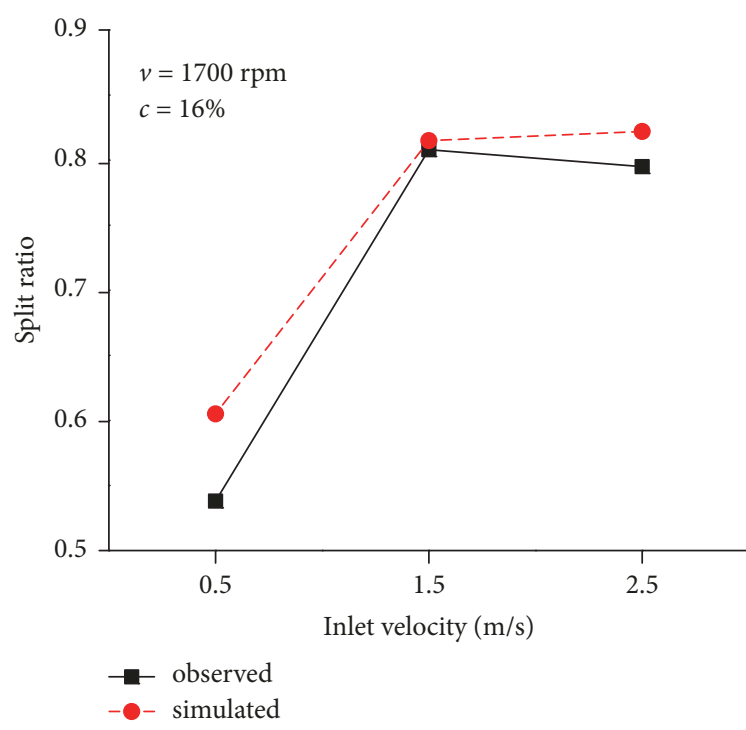

(a) Split ratio $(n=1700 \mathrm{rpm} ; c=16 \%)$

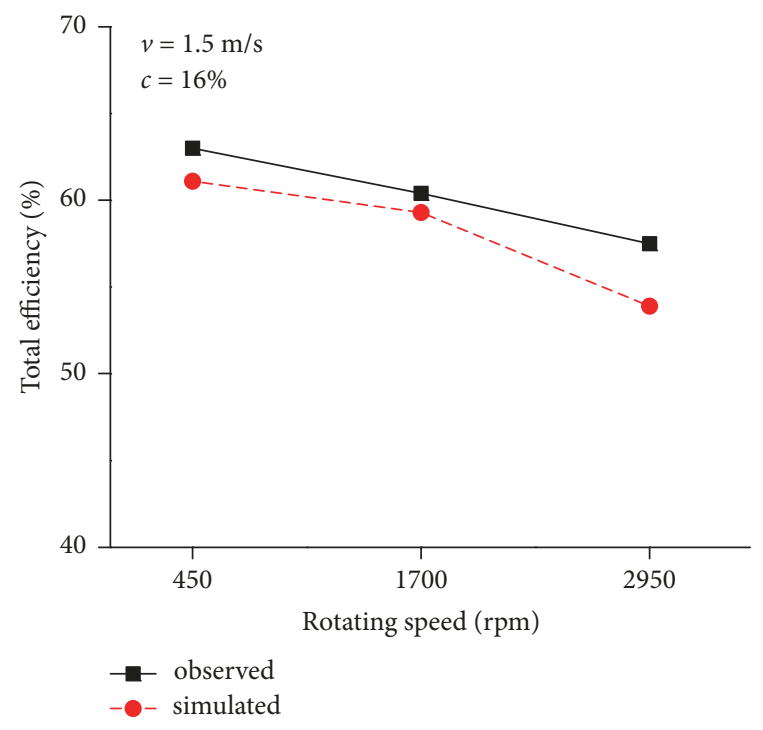

(b) Total efficiency $(v=1.5 \mathrm{~m} / \mathrm{s} ; c=16 \%)$

FIGURE 5: Comparison of experimental results and simulation results.

On the other hand, the centrifugal intensity of the inner vortex is enhanced, which is beneficial to coarse and heavy particles in inner vortex move toward to outer vortex, so that the partition size will be decreased. Tangential velocity of hydrocyclone flow field is the basis for classification and separation work, and the effect of tangential velocity on separation efficiency is significant [25]. For static hydrocyclone, a higher inlet velocity is usually required to achieve a better separation work. However, in the flow field of compound hydrocyclone, the outer vortex can still achieve a higher centrifugal force at lower inlet velocity, which is more favorable for the heavy and coarse particles which accumulate near the cyclone wall.

Figures 6(c) and 6(d) show the evolution of axial velocity in different inlet velocities. It is observed that the axial velocity of inner vortex is gradually increased as the inlet velocity rising, while the axial velocity of outer vortex and the relative space of inner and outer vortex have no obvious changes. This indicates that increasing the inlet velocity can make the discharge of the overflow increase, while the discharge of the underflow is essentially unchanged. The axial velocity directly determines the residence time of the fluid in hydrocyclone, and higher axial velocity will reduce the residence time, which results in the insufficient separation [26]. Therefore, an excessive inlet velocity should not be adopted in compound hydrocyclone.

Figures 6(e) and 6(f) show the evolution of radial velocity in different inlet velocities. It is observed that with the increase of inlet velocity, the radial velocity of inner vortex is increased significantly, while the radial velocity of outer vortex has no obvious regular varieties. This indicates that increasing the inlet velocity can enhance the movement of particles in inner vortex toward the wall.

4.3. The Effect of Rotating Speed ( $n$ ) on Flow Field. The evolution of tangential velocity in different rotating speeds is shown in Figures 7(a) and 7(b). It can be seen that, with the increase of rotating speed, the tangential velocity of both inner and outer vortex are gradually increased and the tangential velocity increment of outer vortex is significantly larger than that of inner vortex. This indicates that increasing the rotating speed can enhance the centrifugal intensity of both inner and outer vortex. Furthermore, the accelerating effect of rotating blade on the outer vortex is obvious more. In the flow field of hydrocyclone, a stronger centrifugal force in outer vortex is favorable for heavy and coarse particles to be confined in the outer vortex, which can avoid more heavy and coarse particles flowing into inner vortex, while a stronger centrifugal force in inner vortex is favorable for heavy and coarse particles which move toward outer vortex, which can decreases the partition size and increases the separation efficiency. Therefore, a higher rotating speed is necessary to improve the performance of compound hydrocyclone. It also can be seen that the tangential velocity is increasing from the wall to the center of hydrocyclone in the rotating speed of $450 \mathrm{rpm}$. This phenomenon can be explained as the inlet velocity larger than the rotating speed, so that the rotation of outer vortex is hindered by the rotating blade. Thus the rotating speed should reach a certain level to ensure the classification performance of compound hydrocyclone.

Figures 7(c) and 7(d) show the evolution of axial velocity in different rotating speeds. It is observed that the axial velocity of inner vortex is gradually increased as the rotating speed increasing, and the boundary between inner and outer vortex moves toward the cyclone wall. This indicates that the space volume of inner vortex is expanded by increasing the rotating speed and the discharge of overflow is increased. It is also observed that increasing the rotating speed can also improve the axial velocity of outer vortex. This can be explained as the radial compression of outer vortex in a higher rotating speed, which enhances the axial movement 


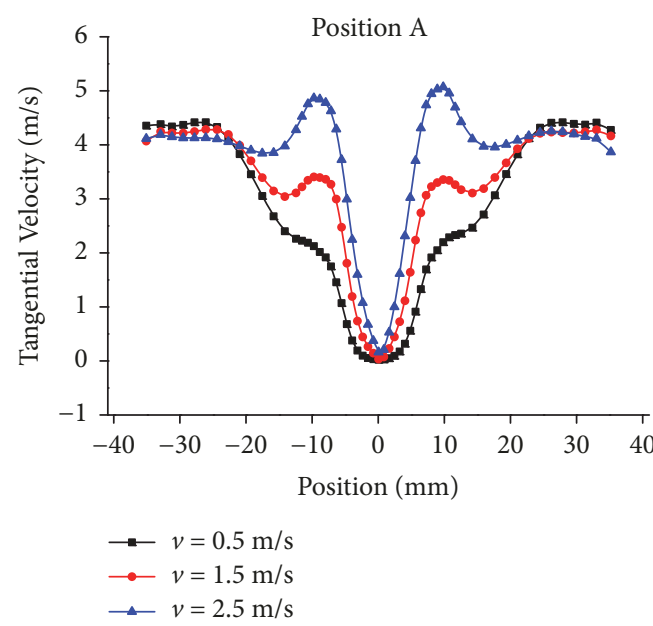

(a) Tangential velocity

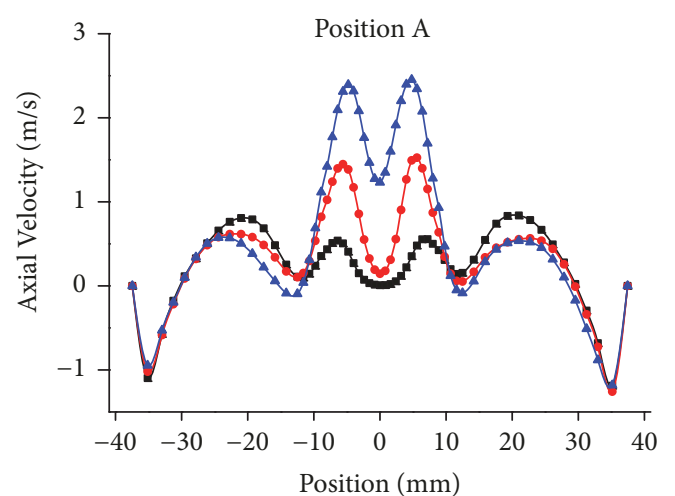

$$
\begin{aligned}
\because v & =0.5 \mathrm{~m} / \mathrm{s} \\
\because v & =1.5 \mathrm{~m} / \mathrm{s} \\
\neg v & =2.5 \mathrm{~m} / \mathrm{s}
\end{aligned}
$$

(c) Axial velocity

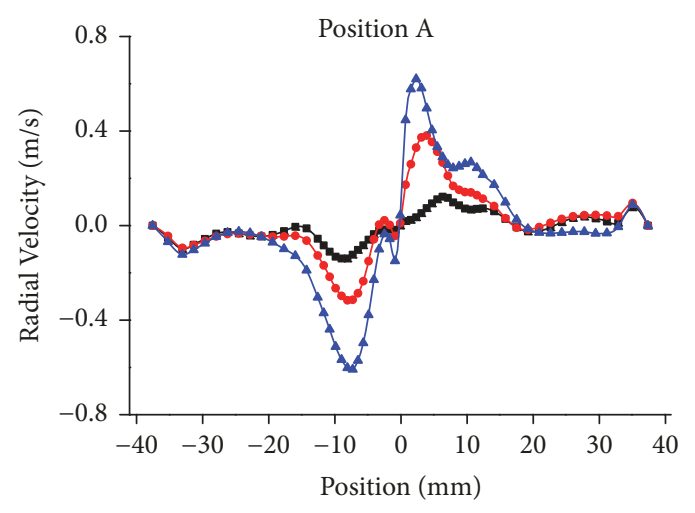

$$
\begin{aligned}
& \longrightarrow v=0.5 \mathrm{~m} / \mathrm{s} \\
& \because v=1.5 \mathrm{~m} / \mathrm{s} \\
& \longrightarrow v=2.5 \mathrm{~m} / \mathrm{s}
\end{aligned}
$$

(e) Radial velocity

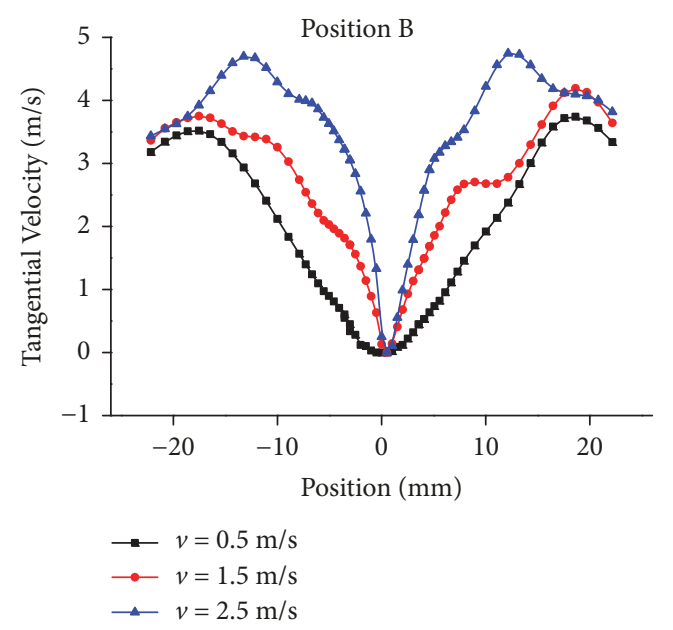

(b) Tangential velocity

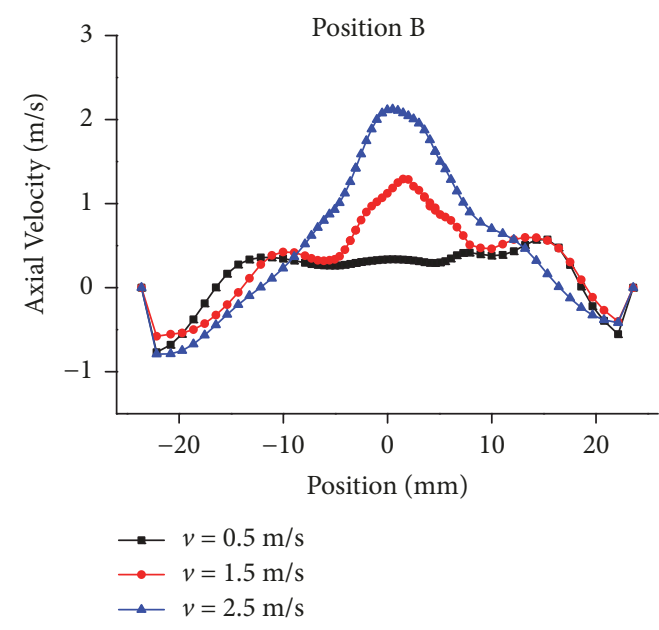

(d) Axial velocity

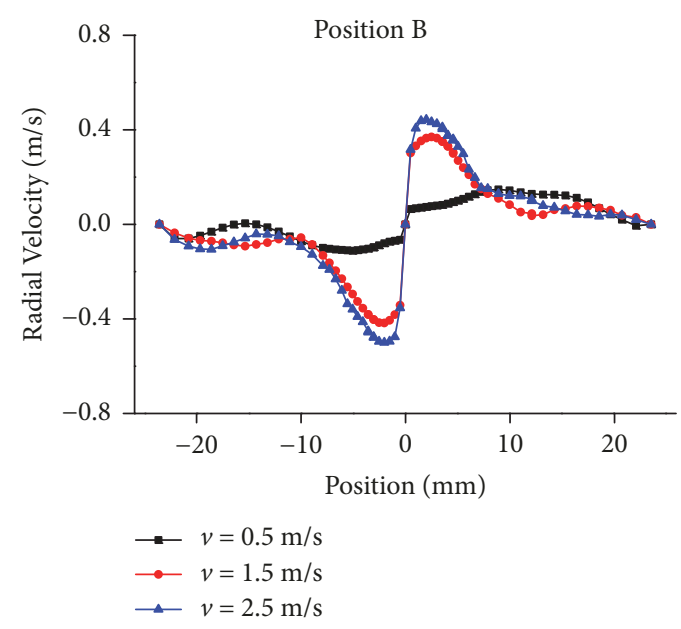

(f) Radial velocity

FIGURE 6: Evolution of velocity-field in different inlet velocities ( $n=1700 \mathrm{rpm} ; c=16 \%$ ). 


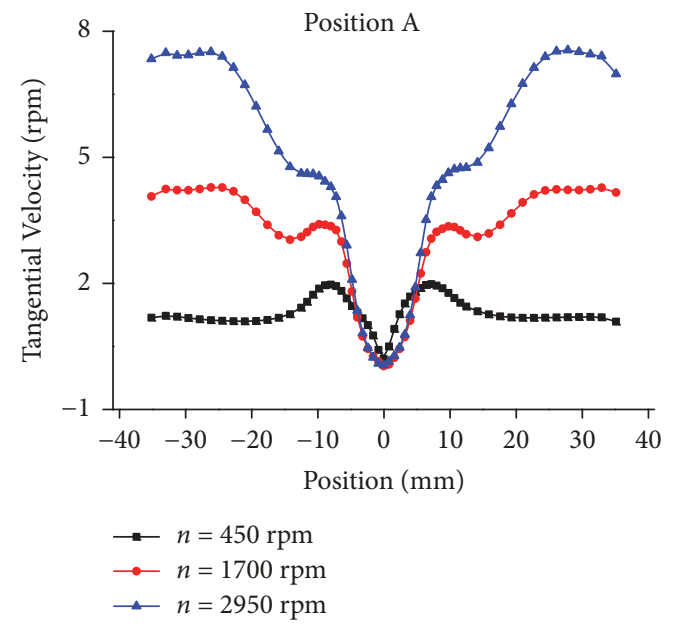

(a) Tangential velocity

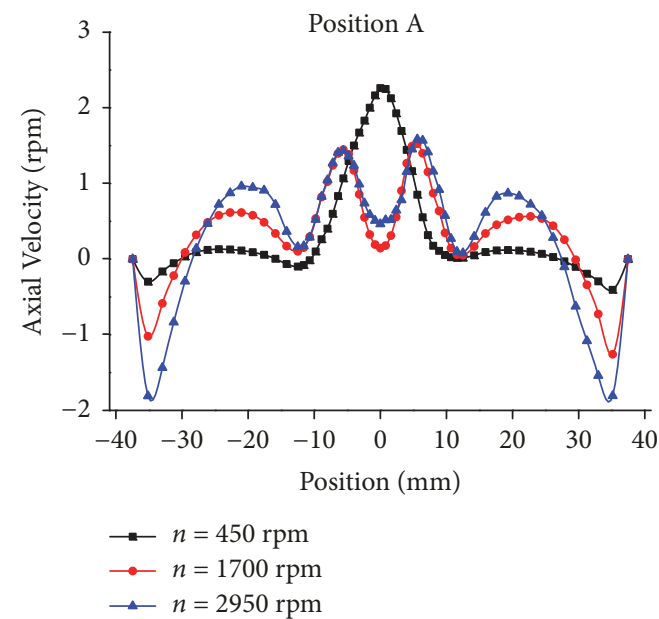

(c) Axial velocity

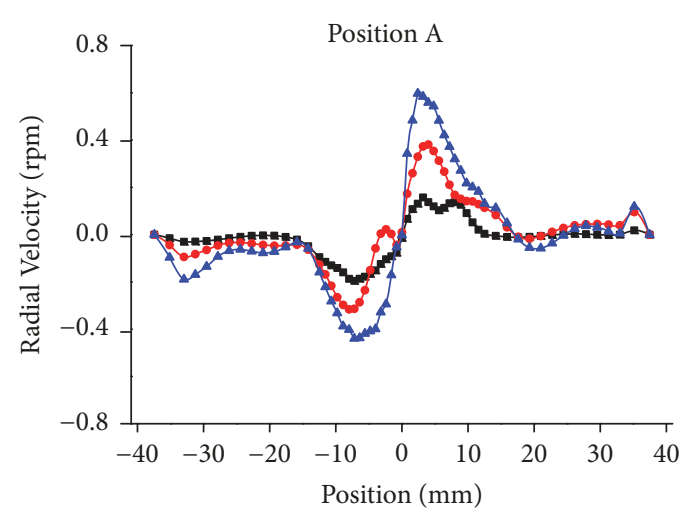

$\longrightarrow n=450 \mathrm{rpm}$
$\because n=1700 \mathrm{rpm}$
$\because n=2950 \mathrm{rpm}$

(e) Radial velocity

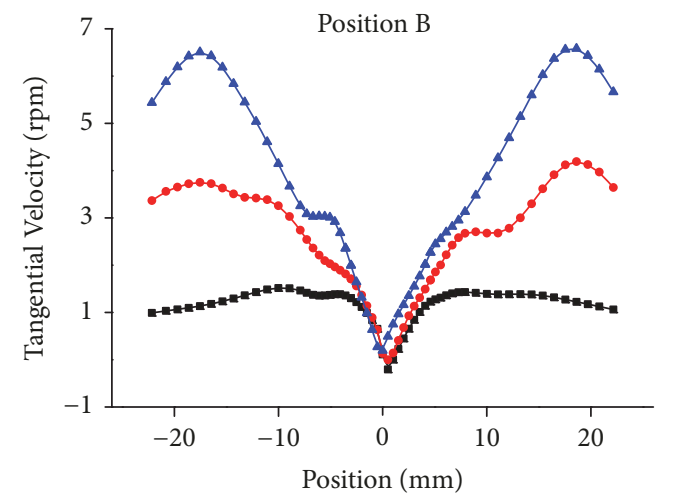

$\longrightarrow n=450 \mathrm{rpm}$
$\longrightarrow n=1700 \mathrm{rpm}$
$\longrightarrow n=2950 \mathrm{rpm}$

(b) Tangential velocity

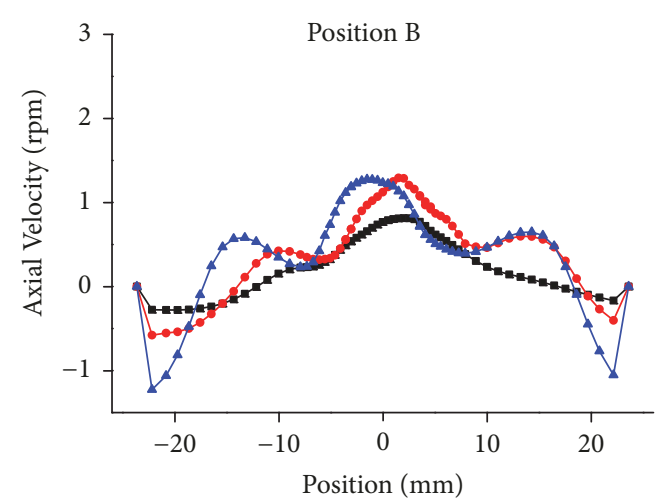

- $n=450 \mathrm{rpm}$

$\rightarrow n=1700 \mathrm{rpm}$

$\multimap n=2950 \mathrm{rpm}$

(d) Axial velocity

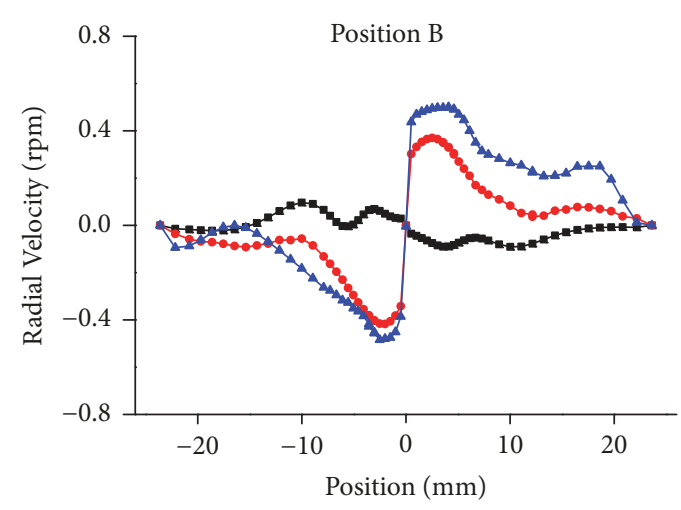

$\longrightarrow n=450 \mathrm{rpm}$
$\because n=1700 \mathrm{rpm}$
$\longrightarrow n=2950 \mathrm{rpm}$

(f) Radial velocity

FIGURE 7: Evolution of velocity-field in different rotating speed $(v=1.5 \mathrm{~m} / \mathrm{s} ; c=16 \%)$. 
TABLE 3: Experimental conditions and results.

\begin{tabular}{|c|c|c|c|c|c|c|c|c|c|}
\hline \multirow{2}{*}{ Number } & \multicolumn{3}{|c|}{ Factors } & \multicolumn{2}{|c|}{$\mathbf{D}_{50}(\mu \mathrm{m})$} & \multicolumn{2}{|c|}{$\mathbf{S}$} & \multicolumn{2}{|c|}{ E (\%) } \\
\hline & $\mathbf{v}$ & $\mathbf{n}$ & c & Observed & Predicted & Observed & Predicted & Observed & Predicted \\
\hline 1 & +1 & +1 & -1 & 17.6 & 17.8 & 0.875 & 0.877 & 65.2 & 64.9 \\
\hline 2 & +1 & -1 & +1 & 29.1 & 29.5 & 0.712 & 0.710 & 51.4 & 51.6 \\
\hline 3 & -1 & +1 & +1 & 23.8 & 24.2 & 0.711 & 0.707 & 59.9 & 59.6 \\
\hline 4 & -1 & -1 & -1 & 21.7 & 21.9 & 0.338 & 0.336 & 79.9 & 80.1 \\
\hline 5 & -1.68 & 0 & 0 & 24.2 & 23.8 & 0.538 & 0.534 & 77.4 & 77.5 \\
\hline 6 & +1.68 & 0 & 0 & 19.5 & 19.1 & 0.795 & 0.798 & 68.3 & 68.4 \\
\hline 7 & 0 & -1.68 & 0 & 26.8 & 26.4 & 0.607 & 0.607 & 63.0 & 62.8 \\
\hline 8 & 0 & +1.68 & 0 & 23.8 & 23.5 & 0.830 & 0.822 & 57.5 & 58.0 \\
\hline 9 & 0 & 0 & -1.68 & 17.2 & 16.5 & 0.838 & 0.841 & 65.4 & 65.6 \\
\hline 10 & 0 & 0 & +1.68 & 27.4 & 26.5 & 0.772 & 0.775 & 44.9 & 45.1 \\
\hline 11 & 0 & 0 & 0 & 21.4 & 21.5 & 0.815 & 0.808 & 61.4 & 60.4 \\
\hline 12 & 0 & 0 & 0 & 20.7 & 21.5 & 0.801 & 0.808 & 60.5 & 60.4 \\
\hline 13 & 0 & 0 & 0 & 21.5 & 21.5 & 0.806 & 0.808 & 61.7 & 60.4 \\
\hline 14 & 0 & 0 & 0 & 20.9 & 21.5 & 0.813 & 0.808 & 59.1 & 60.4 \\
\hline 15 & 0 & 0 & 0 & 21.6 & 21.5 & 0.812 & 0.808 & 59.9 & 60.4 \\
\hline
\end{tabular}

of the fluid in outer vortex. Due to the decrease of flow area in outer vortex, the increase of axial velocity cannot indicate that the discharge of underflow is increased.

Figures 7(e) and 7(f) show the evolution of radial velocity in different rotating speeds. It is observed that, with the increase of rotating, the radial velocity of both inner and outer vortex is increased. This indicates that increasing the rotating speed can enhance the movement of particles toward the cyclone wall.

4.4. The Effect of Feed Concentration (c) on Flow Field. The evolution of tangential velocity in different feed concentrations is shown in Figures 8(a) and 8(b). It can be seen that increasing the feed concentration has a certain level of decelerating effect on tangential velocity. This indicates that the centrifugal intensity of flow field is decreased with the feed concentration increasing, so that the movement of particles toward the hydrocyclone wall is weakened. On the other hand, with the increasing of feed concentration, the particle spacing in the flow field is decreased and the interacting between particles is increased. This may hinder the centrifugal sedimentation of particles and reduce the separation efficiency. Literature [27] suggested that there is a critical value for the effect of feed concentration on separation efficiency. When the feed concentration is less than the critical value, the interaction between particles can be ignored, so that the separation efficiency can be increased with the increasing of feed concentration. However, when the feed concentration is greater than the critical value, the interaction between particles is significant. This seriously hinders the centrifugal sedimentation and results in a sharp decrease of separation efficiency.

Figures 8(c) and 8(d) show the evolution of axial velocity in different feed concentrations. It is observed that, with the increasing of feed concentration, the axial velocity of outer vortex is increased, while the axial velocity of inner vortex is decreased. In addition, the boundary between inner and outer vortex moves toward the center line slightly. This indicates that, in the condition of higher feed concentration, a lower discharge of overflow and a higher discharge of underflow can be obtained.

Figures 8(e) and 8(f) show the evolution of radial velocity in different feed concentrations. It is observed that, with the increase of feed concentration, the radial velocity of inner vortex is gradually decreased, while the radial velocity of outer vortex has no obvious regular varieties. This indicates that increasing the feed concentration will hinder the centrifugal sedimentation of particles which are in inner vortex.

4.5. Regression Model. The results of the observation and prediction for each evaluation index in different operating parameters are summarized in Table 3. Nonlinear regression analysis was used to establish the prediction models to express the partition size $\left(\mathbf{D}_{\mathbf{5 0}}\right)$, split ratio $(\mathbf{S})$, and total efficiency (E) as function of inlet velocity, rotating speed, and feed concentration. In order to investigate the validity and significance of the prediction models, the analysis of variance (ANOVA) was carried out.

The prediction model of partition size $\left(\mathbf{D}_{\mathbf{5 0}}\right)$ obtained by nonlinear regression analysis is as follows:

$$
\begin{aligned}
\mathbf{D}_{50}= & 21.58-7.21 v-2.93 * 10^{-3} n+0.75 c-0.31 v c \\
& -3.63 * 10^{-4} n c+2.22 * 10^{-6} n^{2} .
\end{aligned}
$$

The analysis of variance results for partition size $\left(\mathbf{D}_{\mathbf{5 0}}\right)$ prediction model are shown in Table 4 . It can be seen that the "Model F-value" is 69.31 and "Model $p$ value" is less than 0.0001 . This implies that the model is very significant and there is only a $0.01 \%$ chance that a "Model F-value" of this large may occur due to noise. On the other hand, the "Lack of Fit $F$-value" is 2.45 and "Lack of Fit $p$ value" is 0.1081 . This 


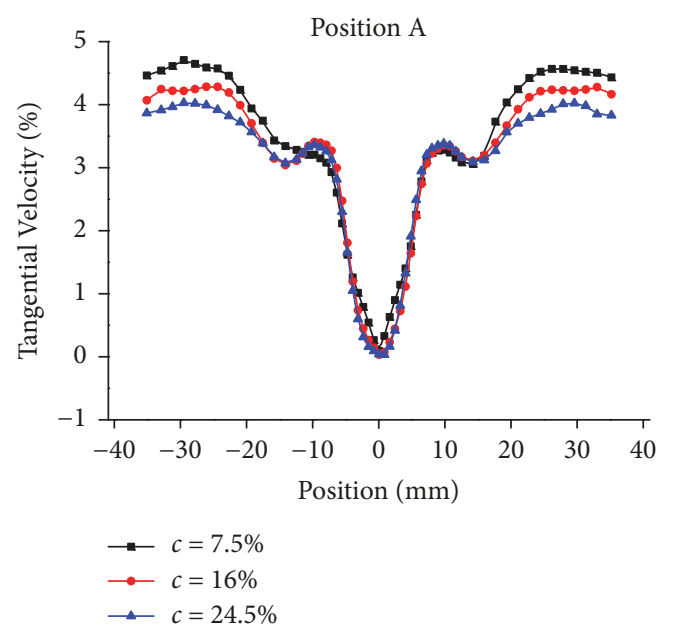

(a) Tangential velocity

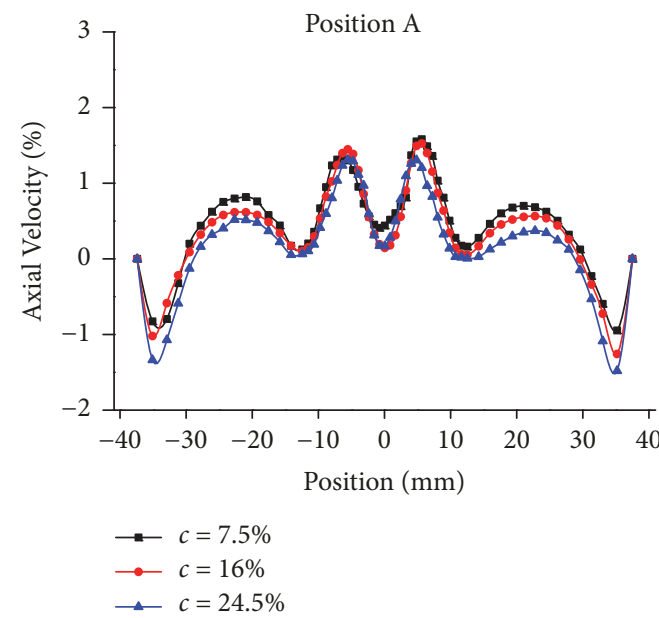

(c) Axial velocity

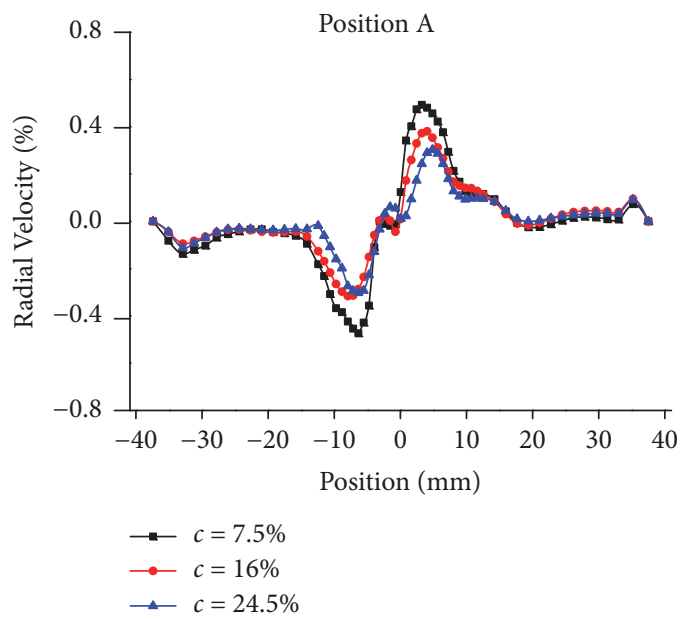

(e) Radial velocity

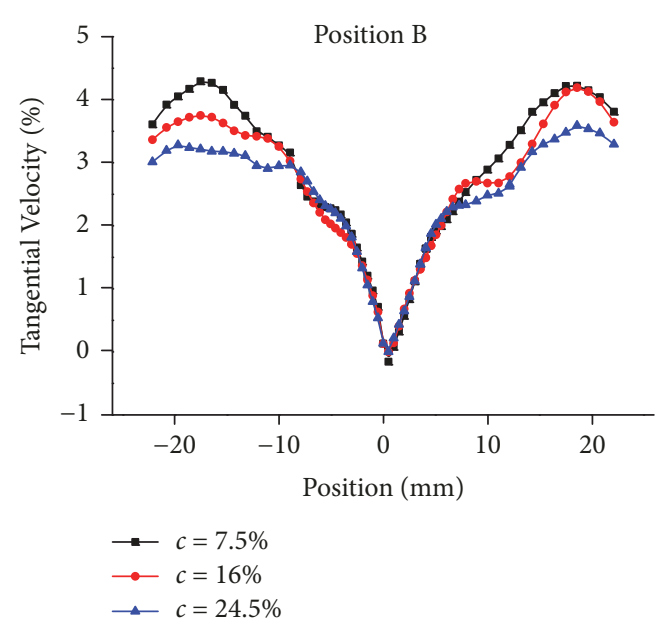

(b) Tangential velocity

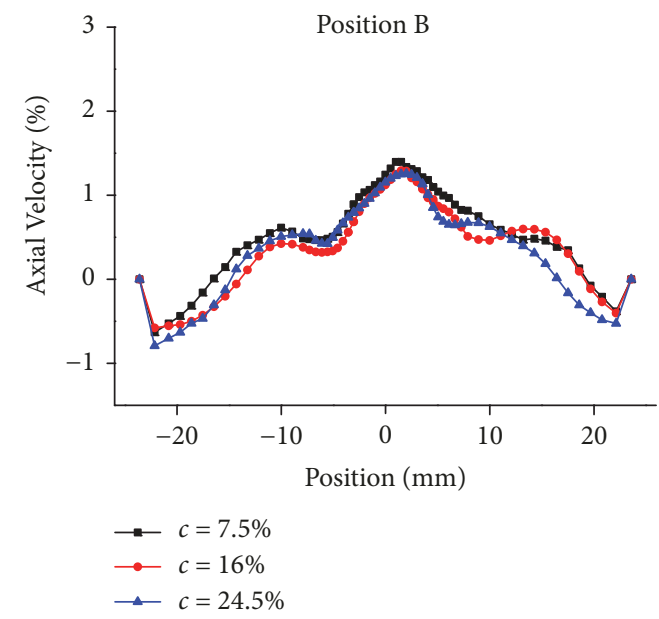

(d) Axial velocity

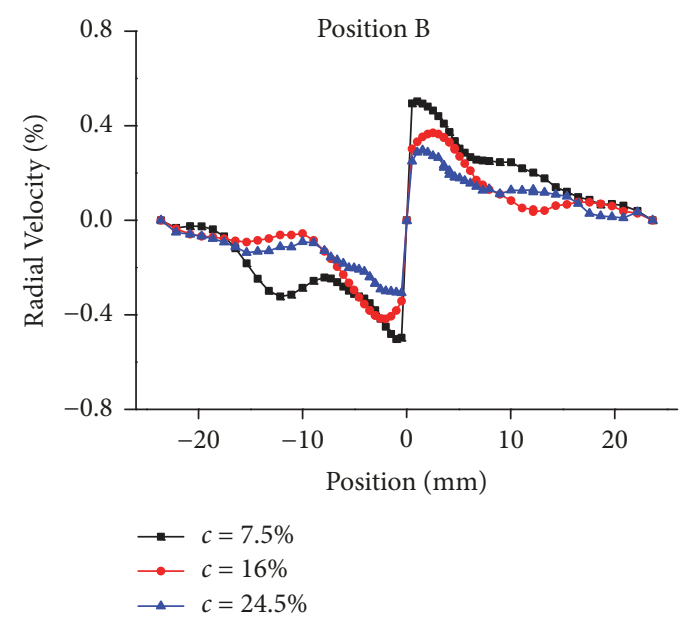

(f) Radial velocity

Figure 8: Evolution of velocity-field in different feed concentration $(v=1.5 \mathrm{~m} / \mathrm{s} ; n=1700 \mathrm{rpm})$. 
TABLE 4: Variance analyses for partition size $\left(\mathbf{D}_{50}\right)$ prediction model.

\begin{tabular}{lcccc}
\hline Term & Sum of squares & Mean square & $F$-value & \\
\hline Model & 159.81 & 26.63 & 69.31 & 28.74 \\
$\mathbf{v}$ & 11.04 & 11.04 & 11.71 & 0.0007 \\
$\mathbf{n}$ & 4.50 & 4.50 & 255.47 & 0.0091 \\
$\mathbf{c}$ & 98.17 & 98.17 & 8.24 & 20.03 \\
vc & 3.17 & 3.17 & 61.52 & 0.0001 \\
nc & 7.70 & 7.70 & 0.0021 \\
$\mathbf{n}^{2}$ & 23.64 & 23.64 & 3.90 \\
Residual & 3.07 & 0.38 & 0.0001 \\
Lack of fit & 2.45 & 0.61 & 0.1081 \\
Pure error & 0.63 & 0.16 & & \\
\hline
\end{tabular}

TABLE 5: Variance analyses for split ratio (S) prediction model.

\begin{tabular}{|c|c|c|c|c|}
\hline Term & Sum of squares & Mean square & $F$-value & $p$ value \\
\hline Model & 0.29 & 0.032 & 822.08 & $<0.0001$ \\
\hline $\mathbf{v}$ & 0.033 & 0.033 & 856.19 & $<0.0001$ \\
\hline $\mathbf{n}$ & 0.025 & 0.025 & 644.64 & $<0.0001$ \\
\hline c & 0.002 & 0.002 & 56.47 & 0.0007 \\
\hline vn & 0.012 & 0.012 & 298.19 & $<0.0001$ \\
\hline vc & 0.006 & 0.006 & 146.93 & $<0.0001$ \\
\hline nc & 0.004 & 0.004 & 98.73 & 0.0002 \\
\hline $\mathbf{v}^{2}$ & 0.031 & 0.031 & 805.85 & $<0.0001$ \\
\hline $\mathrm{n}^{2}$ & 0.012 & 0.012 & 322.02 & $<0.0001$ \\
\hline vnc & 0.002 & 0.002 & 51.65 & 0.0008 \\
\hline Residual & 0.001 & 0.001 & & \\
\hline Lack of fit & 0.001 & 0.001 & 0.54 & 0.5040 \\
\hline Pure error & 0.001 & 0.001 & & \\
\hline
\end{tabular}

implies the lack of fit term is not significant relative to the pure error and there is a $10.81 \%$ chance that a "Lack of Fit F-value" of this large may occur due to noise. All these results indicated that the model described in (6) is effective for partition size $\left(D_{50}\right)$ prediction.

If the $p$ value is $<0.05$, the corresponding term of the model is significant at $5 \%$ level. While the $p$ value $>0.1$ means that the model term is not significant. Therefore, the main factors such as inlet velocity, rotating speed, and feed concentration as well as square of rotating speed have significant effects on the partition size. Among the interactional effects, the interaction between inlet velocity and feed concentration and the interaction between rotating speed and feed concentration have significant effects on partition size. Other effects which are lack of fit terms $\left(\mathbf{v n}, \mathbf{v}^{2}, \mathbf{c}^{2}, \mathbf{v n c}\right)$ have negligible effect on partition size.

The prediction model of split ratio $(\mathbf{S})$ is expressed as follows:

$$
\begin{aligned}
\mathbf{S}= & -1.16+1.22 v+7.98 * 10^{-4} n+0.05 c-2.63 \\
& * 10^{-4} v n-0.03 v c-2.14 * 10^{-5} n c-0.14 v^{2} \\
& -5.52 * 10^{-8} n^{2}+8.95 * 10^{-6} v n c .
\end{aligned}
$$

According to the variance analysis results shown in Table 5, it can be seen that the model is very significant and the lack of fit term is not significant relative to the pure error. Therefore, the model described in (7) is very effective for split ratio (S) prediction. It also can be seen from Table 5 that the main factors such as inlet velocity, rotating speed, and feed concentration as well as square of inlet velocity and square of rotating speed have significant effects on split ratio. Among the interactional effects, the interaction between any two factors and the interaction of the three factors have significant effect on split ratio. Only the square of feed concentration has negligible effect on split ratio.

The prediction model of total efficiency $(\mathbf{E})$ is expressed as follows:

$$
\begin{aligned}
\mathbf{E}= & 117.83-45.97 v-0.01 n+0.31 c+1.91 * 10^{-3} v n \\
& +4.78 * 10^{-4} n c+12.71 v^{2}-0.07 c^{2} .
\end{aligned}
$$

According to the variance analysis results shown in Table 6 , it can be seen that the model is very significant and the lack of fit term is not significant relative to the pure error. Therefore, the model described in (8) is very effective for total efficiency (E) prediction. It also can be seen from Table 6 that the main factors such as inlet velocity, rotating speed, 
TABLE 6: Variance analyses for total efficiency (E) prediction model.

\begin{tabular}{lcccc}
\hline Term & Sum of squares & Mean square & $F$-value & $p$ value \\
\hline Model & 1057.94 & 151.13 & 209.27 & 57.33 \\
$\mathbf{v}$ & 41.40 & 41.40 & 33.75 & 0.0001 \\
$\mathbf{n}$ & 24.37 & 24.37 & 290.96 & 0.0007 \\
$\mathbf{c}$ & 210.13 & 210.13 & 4.00 & 0.0001 \\
$\mathbf{v n}$ & 2.89 & 2.89 & 414.94 & 0.0855 \\
$\mathbf{n c}$ & 13.34 & 13.34 & 73.50 & \\
$\mathbf{v}^{2}$ & 299.66 & 299.66 & 0.0036 \\
$\mathbf{c}^{2}$ & 53.08 & 53.08 & 0.14 \\
Residual & 5.06 & 0.72 & 0.001 \\
Lack of fit & 0.49 & 0.16 & 1.14 & 0.9295 \\
Pure error & 4.57 & &
\end{tabular}

and feed concentration as well as square of inlet velocity and square of feed concentration have significant effects on total efficiency. Among the interactional effects, the interaction between rotating speed and feed concentration has significant effect on total efficiency. Other effects which are lack of fit terms (vc, $\mathbf{n}^{2}$, and vnc) have negligible effect on total efficiency.

4.6. The Effect of Operating Parameters on Partition Size $\left(\mathbf{D}_{50}\right)$. For better understanding, the prediction models of each evaluation index are described by $2 \mathrm{D}$ response surface plots which show the significant interaction of different combination factors. The effect of inlet velocity and feed concentration on $\mathbf{D}_{\mathbf{5 0}}$ of compound hydrocyclone is shown in Figure 9(a). It is observed that, finer particles can be obtained from the vertex finder at higher level of inlet velocity and lower level of feed concentration. This can be explained as the centrifugal intensity of flow field is enhanced, so that the quantity of coarse particles suspended in the inner vortex is decreased. On the other hand, decreasing the feed concentration can make the particle spacing in the flow field increased and the interaction between particles decreased; these lead to the decreasing resistance during the particles centrifugal sedimentation and the quantity reducing of the particles in axial central region. It also can be seen from Figure $9(\mathrm{a})$, the effect of inlet velocity on $\mathbf{D}_{50}$ is gradually weakened with the feed concentration increasing. This is due to the fact that, in the higher concentration flow field, the effect of sedimentation resistance on particles is more obvious.

The effect of rotating speed and feed concentration on $\mathbf{D}_{\mathbf{5 0}}$ of compound hydrocyclone is shown in Figure 9 (b). It is observed that the partition size of compound hydrocyclone will be decreased with the increasing of rotating speed. This is also due to the enhancement of centrifugal intensity in the flow field. However, in the condition of lower feed concentration, an excessive high rotating speed can make the overflow particles coarser. This can be explained as the turbulence and fluctuation of the flow field is enhanced, which seriously disturb the centrifugal sedimentation of particles and finally result in the overflow with coarse particles. With the increasing of feed concentration, the coarsening phenomenon in overflow caused by excessive high rotating speed is gradually eliminated. This can be explained as higher feed concentration increases the fluid viscosity of flow field, which has suppression effect on the unstable flow caused by the rotating blade with high speed.

According to the response surfaces of partition size $\left(\mathbf{D}_{\mathbf{5 0}}\right)$, it can be concluded that, in the condition of $\mathbf{v}=0.5 \mathrm{~m} / \mathrm{s}, \mathbf{n}=$ $450 \mathrm{rpm}$, and $\mathrm{c}=24.5 \%$, this compound hydrocyclone gets the maximum partition size of $35.5 \mu \mathrm{m}$, while in the condition of $\mathbf{v}=2.5 \mathrm{~m} / \mathrm{s}, \mathbf{n}=1275 \mathrm{rpm}$, and $\mathbf{c}=7.5 \%$, this compound hydrocyclone gets the minimum partition size of $11.3 \mu \mathrm{m}$.

4.7. The Effect of Operating Parameters on Split Ratio (S). The effect of inlet velocity and rotating speed on $\mathbf{S}$ of compound hydrocyclone is shown in Figure 10(a). It is observed that greater split ratio can be obtained at higher level of inlet velocity and higher level of rotating speed, so that a bigger discharge of overflow can be achieved. This can be explained as the pressure energy of the flow field is increased with inlet velocity and rotating speed increasing, which enhance the resistance of the cyclone's conical part to outer vortex and expand the volume of inner vortex. However, the split ratio of compound hydrocyclone is decreased slightly in the condition of excessive high inlet velocity and rotating speed. This is due to the fact that the axial velocity of outer vortex is increased significantly, which enhances the discharge ability of the apex pipe.

The effect of inlet velocity and feed concentration on $\mathbf{S}$ is shown in Figure 10(b). It is observed that greater split ratio can be achieved at higher level of inlet velocity and lower level of feed concentration. This can be explained as the effect of gravity on outer vortex is weakened with the decreasing of feed concentration. In addition, decreasing the feed concentration reduces the flow viscosity, which can decrease the kinetic energy loss and increase the pressure in hydrocyclone, so that the flow resistance in cyclone's conical part is increased. It is also noted that, in the condition of lower inlet velocity, raising the feed concentration can make the split ratio increased slightly. This is due to the fact that higher feed concentration causes more particles to accumulate in the apex zone of conical part and then impedes the discharge of the overflow. 


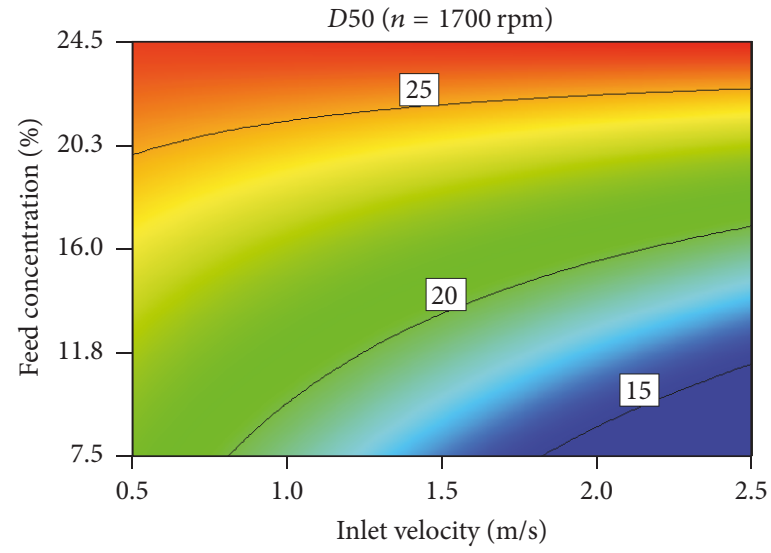

(a)

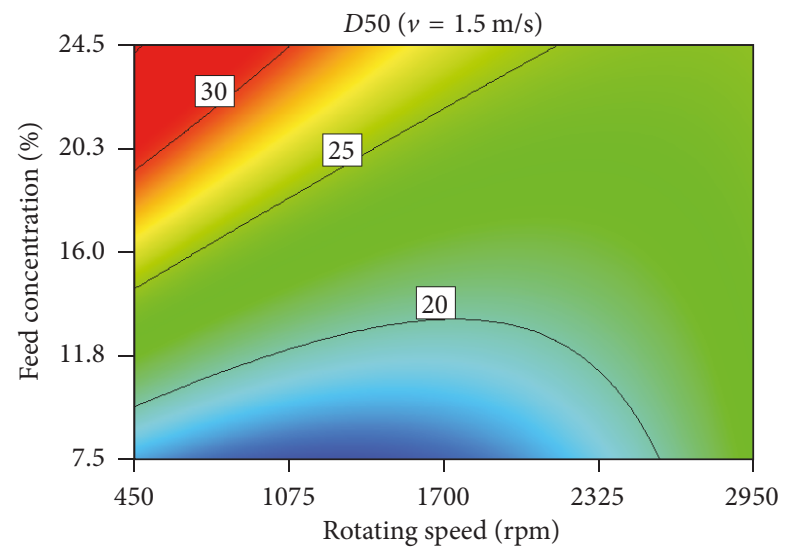

(b)

FIGURE 9: Response surface plot showing the effect of operating parameters on $\mathbf{D}_{\mathbf{5 0}}$.

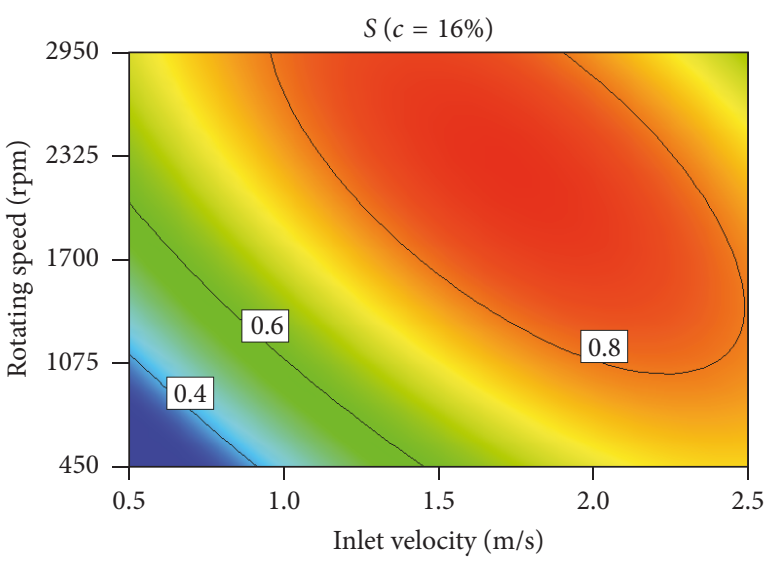

(a)

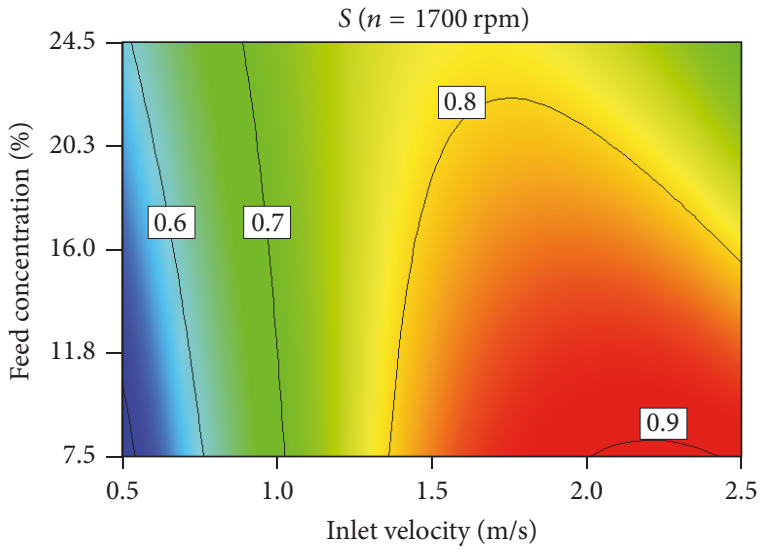

(b)

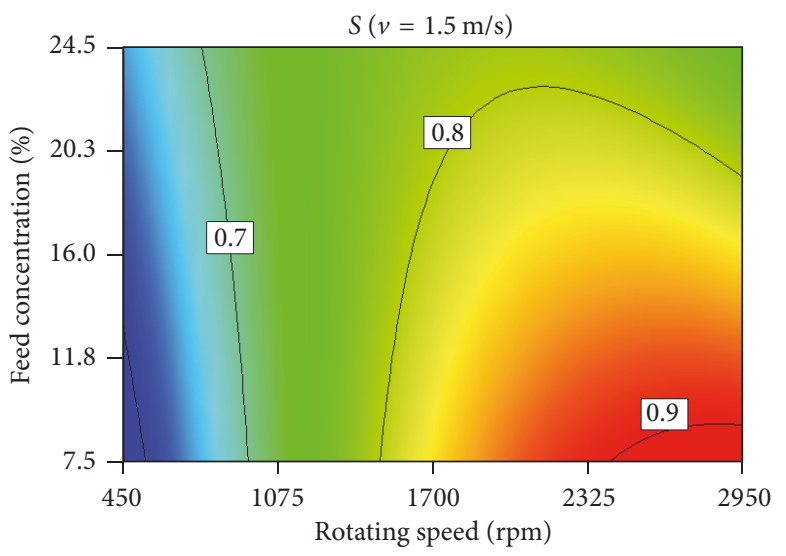

(c)

FIGURE 10: Response surface plot showing the effect of operating parameters on $\mathbf{S}$. 


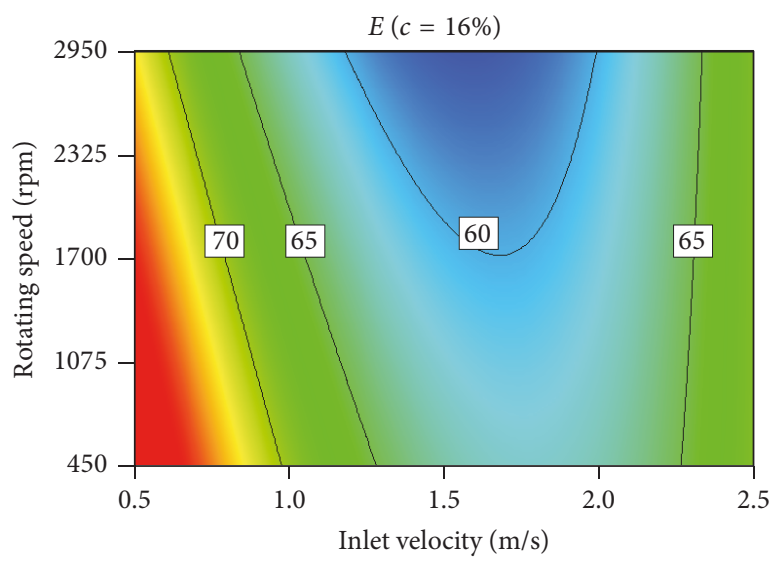

(a)

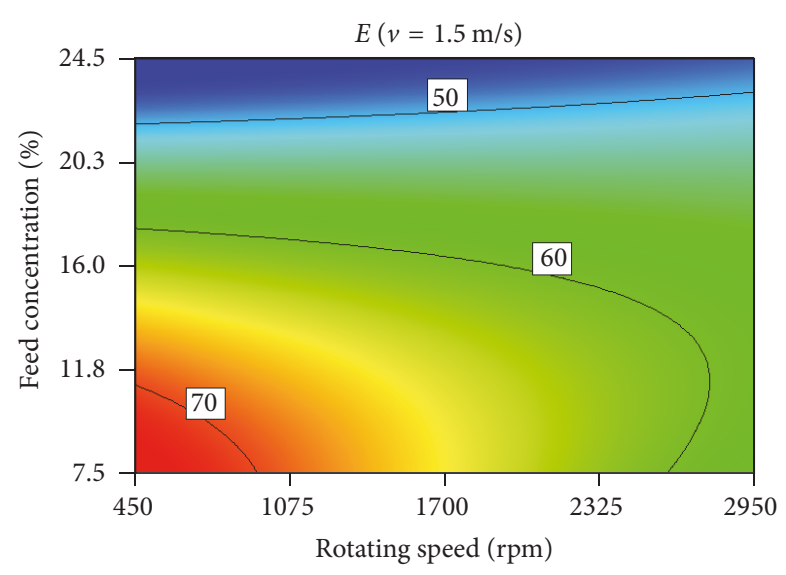

(b)

FIGURE 11: Response surface plot showing the effect of operating parameters on E.

The effect of rotating speed and feed concentration on $\mathbf{S}$ is shown in Figure 10(c). It is observed that, in the condition of higher rotating speed and lower feed concentration, higher level of split ratio can be achieved. Moreover, the interaction between rotating speed and feed concentration is similar to that between inlet velocity and feed concentration.

The response surfaces of split ratio (S) show that the maximum split ratio of compound hydrocyclone is 0.94 and the corresponding operating condition is $\mathbf{v}=2.0 \mathrm{~m} / \mathrm{s}, \mathbf{n}$ $=2200 \mathrm{rpm}$, and $\mathbf{c}=7.5 \%$, while the minimum split ratio of compound hydrocyclone is 0.02 and the corresponding operating condition is $\mathbf{v}=0.5 \mathrm{~m} / \mathrm{s}, \mathbf{n}=450 \mathrm{rpm}$, and $\mathbf{c}=10.5 \%$.

\subsection{The Effect of Operating Parameters on Total Efficiency} (E). The effect of inlet velocity and rotating speed on $\mathbf{E}$ of compound hydrocyclone is shown in Figure 11(a). It is observed that higher total efficiency can be obtained in the condition of lower rotating speed and lower inlet velocity, so that the underflow has a bigger discharge. This can be explained as the space volume of inner vortex is in a lower level, decreasing the quantity of the particles suspended in inner vortex. Nevertheless, the effect of inlet velocity on total efficiency has two sides. It can be seen that when the inlet velocity is at a higher level, the total efficiency will also be increased. This is because the centrifugal force on particles is greater than the sedimentation resistance, so that the radial equilibrium position of particles is closer to the hydrocyclone's wall.

The effect of rotating speed and feed concentration on $\mathbf{E}$ is shown in Figure 11(b). It is observed that higher total efficiency can be obtained at lower level of feed concentration. This can be explained as the sedimentation resistance of particles is weakened with the feed concentration decreasing, so that the number of particles which radial equilibrium positions in inner vortex is decreased. It also can be seen that, in the condition of higher feed concentration, there is a negligible effect on total efficiency as the rotating speed changes. This is because the effect of sedimentation resistance on particles is much greater than that of the centrifugal force.
The response surfaces of total efficiency (E) show that, in the condition of $\mathbf{v}=0.5 \mathrm{~m} / \mathrm{s}, \mathbf{n}=450 \mathrm{rpm}$, and $\mathbf{c}=$ $9.9 \%$, this compound hydrocyclone gets the maximum total efficiency of $90.8 \%$, while in the condition of $\mathbf{v}=1.7 \mathrm{~m} / \mathrm{s}, \mathbf{n}=$ $1060 \mathrm{rpm}$, and $\mathbf{c}=24.5 \%$, this compound hydrocyclone gets the minimum total efficiency of $42.9 \%$.

\section{Conclusion}

The effect of operating parameters on compound hydrocyclone performance is studied using CFD numerical simulation and experimental method. According to the response surfaces of three performance indexes and the simulation results of flow field, some conclusions can be obtained as follows.

(1) As the key component of compound hydrocyclone, rotating blade has significant effects on the flow field and performance indexes. Because of the accelerating function of rotating blade, the centrifugal intensity of hydrocyclone's flow field can get a higher level, so that compound hydrocyclone can be used for separation of finer particles. On the other hand, the flow field of compound hydrocyclone can still achieve a higher centrifugal force in the condition of lower inlet velocity. This is the advantage that static hydrocyclone cannot be compared. However, an excessive higher speed of rotating blade will cause strong fluctuations in the flow field, which seriously disturb the particles centrifugal sedimentation. Therefore, excessive high level of rotating speed should not be adopted.

(2) For this compound hydrocyclone, the results of response surfaces indicate that the partition size range is $11.3 \sim 35.5 \mu \mathrm{m}$, the split ratio range is $0.02 \sim 0.94$, and the total efficiency range is $42.9 \sim 90.8 \%$. In the application of compound hydrocyclone, higher inlet velocity and feed concentration should be adopted to achieve a greater yield capacity; meanwhile, rotating speed should be set to a lower level to reduce the energy consumption. On the other hand, in order to get more particles from the overflow, the compound hydrocyclone should be operated in the condition which 
can achieve higher level of split ratio and lower level of total efficiency. According to the above requirements to optimize the operating parameters, for partition size less than $12 \mu \mathrm{m}$, the optimized operating condition is $\mathbf{v}=2.5 \mathrm{~m} / \mathrm{s}, \mathbf{n}=$ $1865 \mathrm{rpm}$, and $\mathbf{c}=7.5 \%$. The corresponding total efficiency is $72.8 \%$ and split ratio is 0.928 . For partition size less than $35 \mu \mathrm{m}$, the optimized operating condition is $\mathbf{v}=2.5 \mathrm{~m} / \mathrm{s}, \mathbf{n}=$ $905 \mathrm{rpm}$, and $\mathrm{c}=24.5 \%$. The corresponding total efficiency is $49.8 \%$ and split ratio is 0.638 .

\section{Nomenclature}

$\mathbf{D}_{\mathbf{i}}$ : Inlet diameter $(\mathrm{mm})$

$\mathbf{D}_{\mathbf{o}}$ : Vortex finder diameter $(\mathrm{mm})$

$\mathbf{D}_{\mathbf{u}}$ : Apex diameter $(\mathrm{mm})$

D: Cylindrical diameter $(\mathrm{mm})$

d: Rotating blade diameter $(\mathrm{mm})$

L: Cylindrical length ( $\mathrm{mm})$

l: Rotating blade length $(\mathrm{mm})$

$\boldsymbol{\theta}$ : Cone angle $\left({ }^{\circ}\right)$

v: Inlet velocity $(\mathrm{m} / \mathrm{s})$

n: Rotating speed (rpm)

c: Feed concentration by mass (\%)

$\mathbf{D}_{\mathrm{S}}$ : Partition size of overflow $(\mu \mathrm{m})$

S: Split ratio of overflow

R: Recovery rate (\%).

\section{Conflicts of Interest}

The authors declare that they have no conflicts of interest.

\section{Acknowledgments}

The authors would like to express their sincere thanks to the National Natural Science Foundation of China (Grant no. 51264034).

\section{References}

[1] P.-K. Liu, L.-Y. Chu, J. Wang, and Y.-F. Yu, "Enhancement of hydrocyclone classification efficiency for fine particles by introducing a volute chamber with a pre-sedimentation function," Chemical Engineering \& Technology, vol. 31, no. 3, pp. 474-478, 2010.

[2] J. D. Boadway, "A hydrocyclone with recovery of velocity energy," in Proceedings of the Second International Conference on Hydrocyclones, pp. 99-108, Bath England, 1984.

[3] T. Larsson, "A new type of hydrocyclone," in Proceedings of the First International Conference on Hydrocyclones, pp. 83-97, Cambridge, UK, 1980.

[4] L. Chu, W. Chen, and Q. Luo, "Separation characteristics of the hydrocyclone with a central cone and annular teeth," Transactions of Nonferrous Metals Society of China, vol. 6, no. 4, pp. 11-15, 1996.

[5] W. K. Evans, A. Suksangpanomrung, and A. F. Nowakowski, "The simulation of the flow within a hydrocyclone operating with an air core and with an inserted metal rod," Chemical Engineering Journal, vol. 143, no. 1-3, pp. 51-61, 2008.

[6] R. Sripriya, M. D. Kaulaskar, S. Chakraborty, and B. C. Meikap, "Studies on the performance of a hydrocyclone and modeling for flow characterization in presence and absence of air core," Chemical Engineering Science, vol. 62, no. 22, pp. 6391-6402, 2007.

[7] M. Ghodrat, S. B. Kuang, A. B. Yu, A. Vince, G. D. Barnett, and P. J. Barnett, "Numerical analysis of hydrocyclones with different conical section designs," Minerals Engineering, vol. 62, pp. 7484, 2014.

[8] M. Ghodrat, S. B. Kuang, A. B. Yu, A. Vince, G. D. Barnett, and P. J. Barnett, "Numerical analysis of hydrocyclones with different vortex finder configurations," Minerals Engineering, vol. 63, pp. 125-138, 2014.

[9] X. M. Liu, F. Li, M. H. Jiang et al., "Test research on oil-water separation of the compound hydrocyclone," China Petroleum Machinery, vol. 30, pp. 1-3, 2002.

[10] M. H. Jiang, Z. C. Wang, X. M. Liu et al., "Structural design of compound hydrocyclones for oil-water separation," Fluid Machinery, vol. 30, pp. 17-19, 2002.

[11] Z. C. Wang, "Numerical simulation of internal flow field in compound hydrocyclone," Acta Petrolei Sinica, vol. 26, pp. 125128, 2005.

[12] S. Li, Z. Wang, F. Lv, Y. Xu, and J. Zhang, "Study on separation performance of the compound hydrocyclone under selfvibration condition," in Proceedings of the 28th International Conference on Ocean, Offshore and Arctic Engineering, OMAE '09, pp. 71-77, USA, June 2009.

[13] C. Liu, L. I. Feng, and Y. U. Yonghong, "Radial Pressure Distribution and Unit Production Ability Determination of Compound Hydrocyclones," Chemical Engineering \& Machinery, vol. 80, pp. 125-130, 2009.

[14] R. Ying, J. Yu, W. Wang, T. Zhang, J. Feng, and S. Du, "Optimization of Structural and Process Parameters for Fine Particle Classifying Hydrocyclone," Jixie Gongcheng Xuebao/Journal of Mechanical Engineering, vol. 53, no. 2, pp. 124-134, 2017.

[15] J. Huang, L. An, and Z. Wu, "Study on Application and Operation Optimization of Hydrocyclone for Solid-liquid Separation in Power Plant," Lecture Notes in Engineering \& Computer Science, vol. 2178, pp. 297-299, 2009.

[16] L. Svarovsky, "Hydrocyclones," in Solid-Liquid Separation, chapter 7, pp. 191-245, Elsevier, 4th edition, 2001.

[17] P. Dixit, R. Tiwari, A. K. Mukherjee, and P. K. Banerjee, "Application of response surface methodology for modeling and optimization of spiral separator for processing of iron ore slime," Powder Technology, vol. 275, pp. 105-112, 2015.

[18] S. B. Kuang, K. W. Chu, A. B. Yu, and A. Vince, "Numerical study of liquid-gas-solid flow in classifying hydrocyclones: Effect of feed solids concentration," Minerals Engineering, vol. 31, pp. 1731, 2012.

[19] S. Ergun, "Fluid flow through packed columns," Chemical Engineering Progress, vol. 48, pp. 89-94, 1952.

[20] C. Y. Wen and Y. H. Yu, "Mechanics of fluidization," Chem Eng Prog Symp Series, vol. 62, pp. 100-111, 1966.

[21] M. Narasimha, M. Brennan, and P. N. Holtham, "Large eddy simulation of hydrocyclone-prediction of air-core diameter and shape," International Journal of Mineral Processing, vol. 80, no. 1, pp. 1-14, 2006.

[22] M. Saidi, R. Maddahian, B. Farhanieh, and H. Afshin, "Modeling of flow field and separation efficiency of a deoiling hydrocyclone using large eddy simulation," International Journal of Mineral Processing, vol. 112-113, pp. 84-93, 2012.

[23] M. Ghodrat, Z. Qi, S. B. Kuang, L. Ji, and A. B. Yu, "Computational investigation of the effect of particle density on the 
multiphase flows and performance of hydrocyclone," Minerals Engineering, vol. 90, pp. 55-69, 2016.

[24] M. Ghodrat, S. B. Kuang, A. B. Yu, A. Vince, G. D. Barnett, and P. J. Barnett, "Computational study of the multiphase flow and performance of hydrocyclones: Effects of cyclone size and spigot diameter," Industrial \& Engineering Chemistry Research, vol. 52, no. 45, pp. 16019-16031, 2013.

[25] S. R. Knowles, D. R. Woods, and I. A. Feuerstein, "The velocity distribution within a hydrocyclone operating without an air core," The Canadian Journal of Chemical Engineering, vol. 51, no. 3, pp. 263-271, 2010.

[26] Z. Stegowski and J.-P. Leclerc, "Determination of the solid separation and residence time distributions in an industrial hydrocyclone using radioisotope tracer experiments," International Journal of Mineral Processing, vol. 66, no. 1-4, pp. 67-77, 2002.

[27] J. S. Qiu, W. M. Chen, Y. Du et al., "Effects of solid content particle size and setting angle on separation performance of a hydrocyclone," Journal of Filtration \& Separation, vol. 5, pp. 36, 1995. 


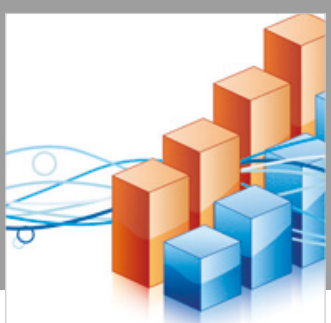

Advances in

Operations Research

\section{-n-m}
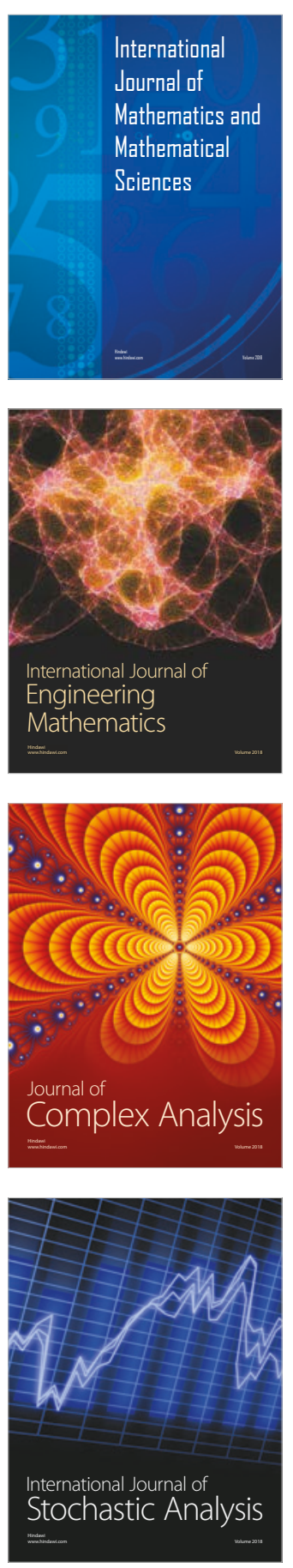
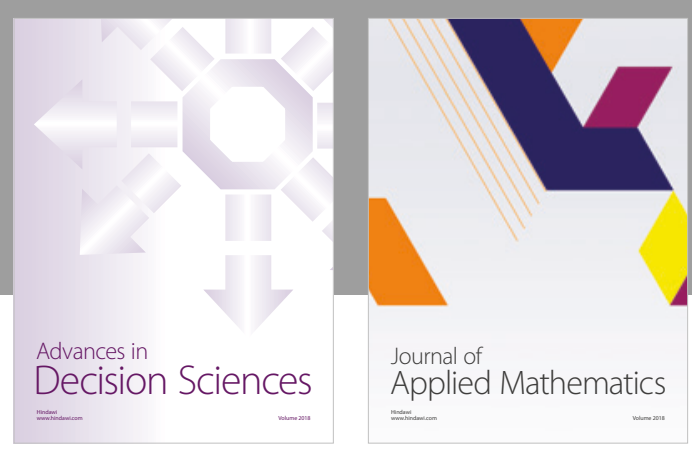

Journal of

Applied Mathematics
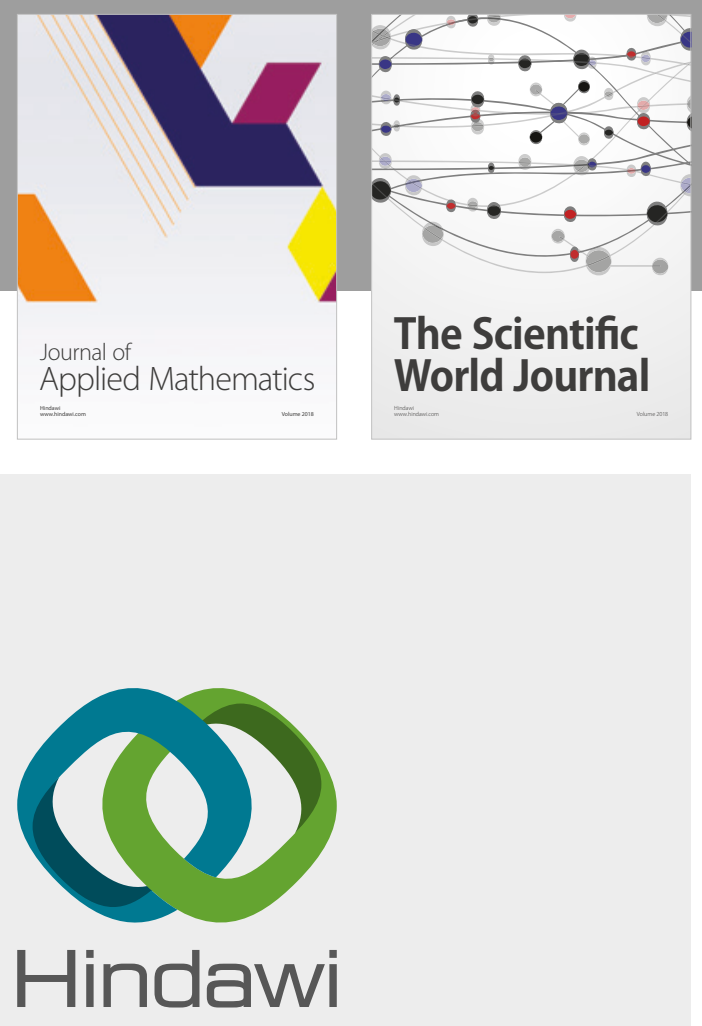

Submit your manuscripts at

www.hindawi.com

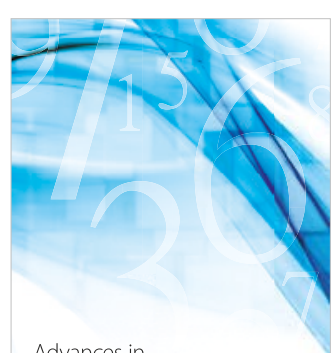

Advances in
Numerical Analysis
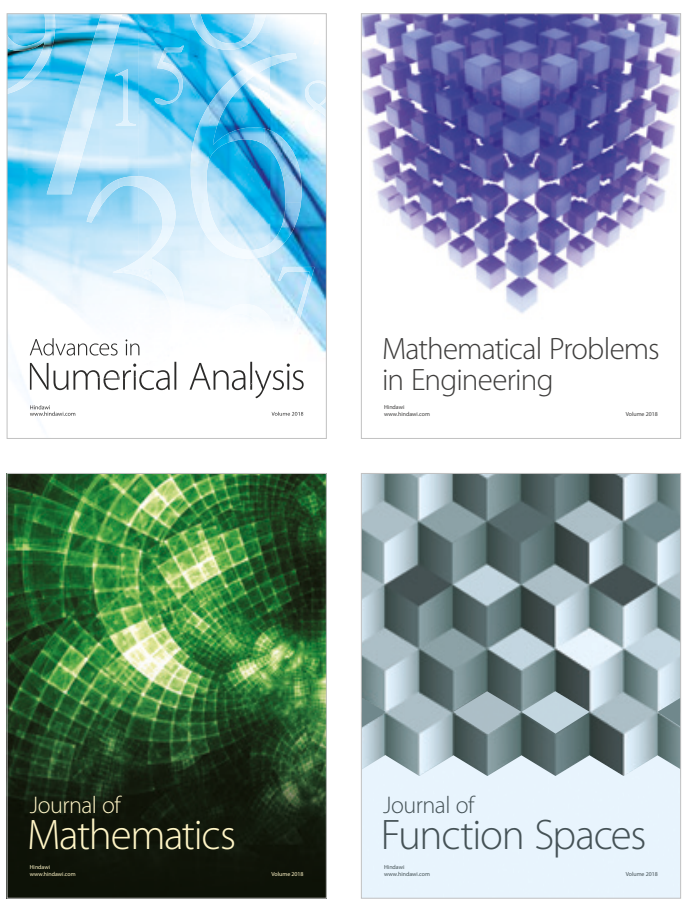

Mathematical Problems in Engineering

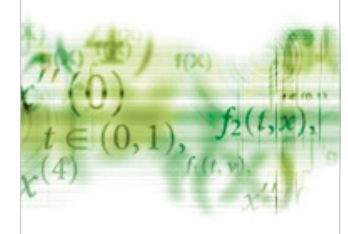

International Journal of

Differential Equations

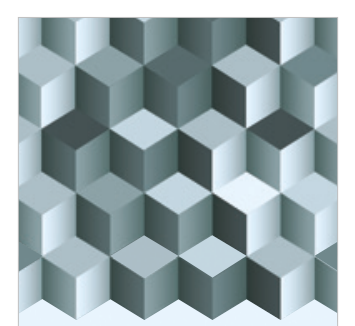

Journal of

Function Spaces

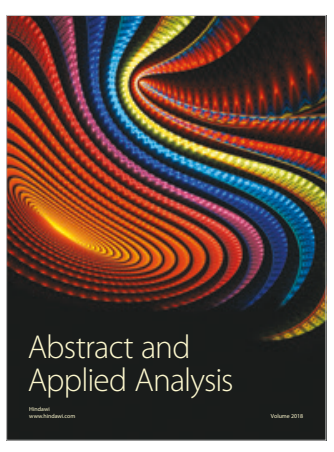

The Scientific

World Journal

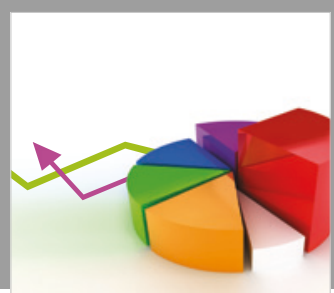

Journal of

Probability and Statistics
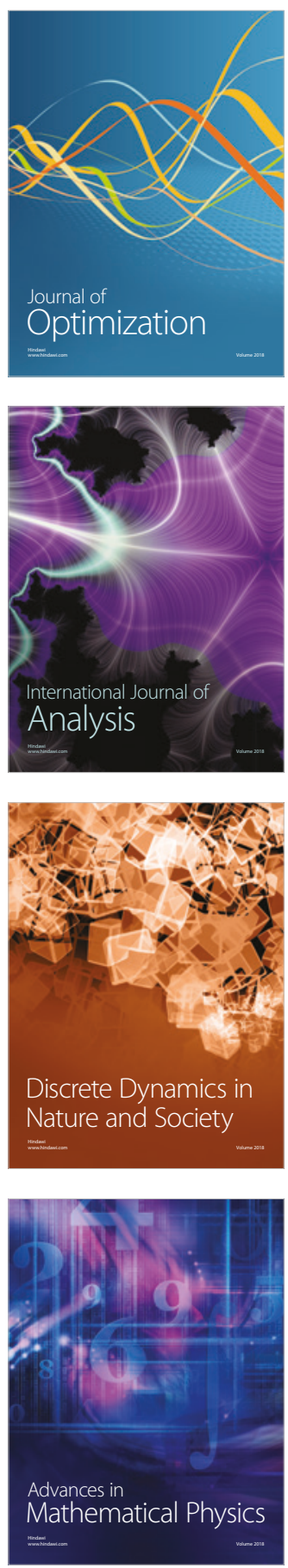